\title{
DE GALICIA A FLANDES: RECLUTAMIENTO Y SERVICIO DE SOLDADOS GALLEGOS EN EL EJÉRCITO DE FLANDES $(1648-1700)^{*}$
}

\author{
Antonio José Rodríguez Hernández \\ Instituto Universitario de Historia Simancas-Universidad de Valladolid-CSIC
}

\begin{abstract}
RESumen. Durante el siglo XVII en el reino de Galicia se realizaron importantes reclutamientos de soldados para Flandes, además de abundantes expediciones marítimas que transportaban a estos hombres a su destino. Pese a que habitualmente se ha creído que las aportaciones de Galicia -al igual que el resto de las llegadas de españoles al ejército de Flandes- no fueron importantes a partir de la década de 1640, lo cierto es que los reclutas gallegos no pararon de llegar a los Países Bajos durante todo el siglo para luchar en los enfrentamientos bélicos de la Monarquía Hispánica. Especialmente relevante será la aportación de Galicia tras la paz con Portugal (1668), enviándose a partir de esa fecha más de 16.000 hombres a Flandes. En este presente artículo hemos realizado una aproximación al reclutamiento de los soldados gallegos, diferenciando los distintos métodos por los que se realizaban las reclutas y el transporte de los hombres hasta Flandes. Igualmente hemos querido estudiar los tercios gallegos que se crean en Flandes a raíz de las aportaciones del reino y el servicio de los soldados gallegos en ese ejército.
\end{abstract}

Palabras clave: Galicia, Siglo XVII, Ejército de Flandes, reclutamiento, guerra, soldados, transporte marítimo, Tercios, emigración, frontera con Portugal.

AbSTRACT. During $17^{\text {th }}$ century in the Spanish kingdom of Galicia, numerous soldiers were recruited to Flanders, in addition to many maritime expeditions that carried all those men to their destination. Although people have thought that the contribution of the kingdom of 2007.

* Trabajo recibido el 19 de diciembre de 2006 y admitido para su publicación el 23 de febrero de 
Galicia, as well as the others arrivals of Spanish soldiers in the army of Flanders, were not important from 1640. New enlisted men from Galicia were arriving during all the $17^{\text {th }}$ century to take part in the war. The contribution of Galicia was very significant after the peace treaty with Portugal in 1668, since more than 16.000 soldiers were sen to Flanders from then on. In this article, we have made an approach to the recruitment of soldiers in Galicia and their transport to Flanders, studying the different methods. Also, we have researched on Tercios of Galicia created in Flanders and their services to the army as result of the arrival of soldiers of the kingdom.

Keywords: Galicia, $17^{\text {th }}$ century, Army of Flanders, recruitment, war, soldiers, maritime transport, Tercios, emigration, Portuguese frontier.

A LO LARGO del siglo XVII la Monarquía Hispánica encontrará en el Reino de Galicia una verdadera mina de hombres para sus ejércitos, siendo muchos de estos soldados enviados al ejército de Flandes. Lo cierto es que el reino de Galicia era una región muy potente demográficamente en el conjunto de la Corona de Castilla, pero sólo en casos excepcionales había aportado masivamente hombres a la monarquía antes de finales del siglo XVI. De una manera muy limitada podemos ver tropas gallegas en la reconquista de Granada y en otras acciones puntuales, pero sin duda su cuantía era muy inferior a la de su potencial demográfico. Durante la primera mitad del siglo XVII, a raíz de las primeras expediciones marítimas a Flandes con base en Galicia, se gestará el sistema de reclutamiento de gallegos a Flandes, pero sobre todo unas bases militares y de aprovisionamiento que conformen un nuevo Camino Español por mar, en el que Galicia era una pieza clave y un nudo de comunicaciones ${ }^{1}$. Pero el sistema militar y reclutador gallego, puesto a plena potencia en la década de 1630, será perfeccionado durante el largo y cruento enfrentamiento fronterizo con Portugal, tras la rebelión desatada en 1640 por los portugueses. Ambas experiencias confluirán, especialmente a partir de 1668, para que a lo largo de todo el siglo XVII el reino de Galicia sea la zona geográfica española que más hombres aporte a los tercios españoles del ejército de Flandes.

\section{El Reclutamiento: Una aproximación al reclutamiento en Galicia para Flandes}

Durante la primera mitad del siglo XVII habían salido desde Galicia para Flandes gran número de hombres en distintas expediciones. En un memorial dado por el

1 Este tema ha sido tratado por: SAAVEDRA VÁZQUEZ, María del Carmen: Galicia en el Camino de Flandes, Coruña, 1996. 
reino, fechado entre 1653-56, los procuradores gallegos informaban al rey de que: "En tiempo que governaron el dicho Reyno el Marqués de Espinardo, el Marqués de Mancera, y el Marqués de Valparaíso, se sacaron solo para los estados de Flandes 24.000 infantes, como costa de las listas de embarcaciones"'. Si bien esta cifra es seguramente algo exagerada, los gobernadores citados estuvieron a cargo del gobierno de Galicia desde 1626 a 1642, lo que posibilitaría que la afirmación fuera en parte cierta, aunque el número enviado estaría muy abultado. En fechas anteriores las propias en las propias Juntas Generales del reino se encargan de mitificar aun más estas cifras, estimando la salida de gallegos para Flandes en 28.000 hombres e incluso en más de 38.000, a la vez que en otras ocasiones se dice que las aportaciones totales del reino, tanto en Flandes, como en Fuenterrabía, Perpinán y Salces ascendieron a 34.000 hombres, fundamentalmente en el periodo de entre 1630-16423.

Está claro que la aportación gallega en ese periodo para Flandes fue notable, pero las cuentas en ningún caso cuadran, y menos cuando acudimos a otros estudios que nos informan de los embarques de tropas españolas para Flandes realizados por el profesor G. Parker en su mítica obra sobre el Camino Español ${ }^{4}$, o los estudios realizados para Galicia en este periodo por la profesora $\mathrm{M}^{\mathrm{a}} \mathrm{C}$. Saavedra Vázquez ${ }^{5}$. Incluso si tuviéramos en cuenta como tropas gallegas todos los hombres llegados a Flandes por mar durante en este periodo en ningún caso llegaríamos a alcanzar las cifras alegadas por las juntas. Este elevado número de hombres nunca se envió a Flandes, ya que las cifras más bien corresponderían a todo el esfuerzo militar del reino, ya fuera para Flandes, como para los presidios, Fuenterrabía, la Armada y los milicianos enviados a la misma frontera del reino.

La verdadera sangría humana gallega en los campos de batalla de Flandes llegará posteriormente, durante una época mucho más oscura y desconocida, la segunda mitad del siglo XVII y especialmente el reinado de Carlos II "El hechizado". A lo largo de los últimos meses de 1667 y durante todo el año 1668 se va a gestionar en Galicia una movilización de tropas para Flandes sin parangón a lo largo de la historia, al enviarse a los Países Bajos buena parte del ejército que defendía la frontera del reino, totalizando algo menos de 6.000 hombres. Ni siquiera la expedición de Oquendo de 1639,

2 Memorial impreso del reino de Galicia al Rey en relación de los servicios que ha realizado el reino. Biblioteca Nacional de Madrid, Manuscrito 2.384 p. 354 y ss (en adelante B.N.Madrid. Mmss. 2.384). Sin fechar, aunque se piensa que fue entre 1653-56.

3 Juntas del Reino del 23 de julio 1642, 10 de febrero 1643, 11 de mayo 1644 y 9 de julio 1646. Documentos 10-A, 29-A, 39-A y 73-A. Actas de las Juntas del Reino de Galicia. Tomo V: 1642-1647, Santiago de Compostela, 1995.

4 PARKER, Geoffrey: El ejército de Flandes y el Camino Español 1567-1659, Madrid, 1991.

5 SAAVEDRA VÁZQUEZ, María del Carmen: Galicia en el Camino de Flandes, Coruña, 1996. 
en la supuestamente "se embarcaron a punta de pistola dos mil padres y esposos de la región de La Coruña”, supondrá una movilización de gallegos hacia Flandes tan numerosa.

Durante el enfrentamiento con Portugal esporádicamente también se realizaron distintas levas en Galicia para Flandes, aunque su cuantía no fue demasiado elevada, al mantenerse en el reino un ejército casi exclusivamente formado por soldados gallegos para defender la frontera. Pero con la definitiva paz con los portugueses, en 1668, se posibilitará la salida del reino de gran parte del nutrido grupo de sus naturales encargados de la defensa de sus fronteras. A partir de esa fecha la salida de soldados gallegos a Flandes quedará posibilitada, lo que supondrá importantes reclutamientos en el reino para Flandes durante las dos décadas siguientes, llegándose a enviar desde ese periodo más de 16.000 soldados gallegos a Flandes, lo que constituye prácticamente la mitad de los españoles enviados a Flandes durante el reinado de Carlos II.

\section{a) El dificil reclutamiento de voluntarios en el reino de Galicia}

El modelo de reclutamiento empleado en el reino de Galicia variará respecto al utilizado en el resto de Castilla, ya que en el reino la obtención de voluntarios era muy difícil de conseguir. Los naturales del reino siempre se mostraban poco dispuestos a salir de sus casas como soldados, teniendo la mayoría poca vocación militar. Este era un problema que ya venía produciéndose desde finales del siglo XVI y que se agravará en la década de 1630, cuando la monarquía empiece a exigir al reino una aportación militar sin parangón hasta ese momento ${ }^{7}$. Hasta esa década eran aún pocos los gallegos que se habían inclinado por la vida militar, faltando incluso mandos capacitados y con experiencia para las primeras reclutas realizadas.

El problema de fondo era que en muy pocas ocasiones se habían realizado reclutamientos voluntarios en el reino a cargo del viejo sistema de reclutamiento administrativo, por el que un capitán arbolaba su bandera en una ciudad y comenzaba a captar voluntarios. Esto no significaba que el rey no pudiera reclutar hombres en el reino -ya fuera en tierras de realengo, señoriales o de la iglesia-, sino que muy posiblemente el reclutamiento administrativo no se había extendido en el reino, por lo

6 PARKER, Geoffrey: El ejército de Flandes y el Camino Español 1567-1659, Madrid, 1991, Op. Cit. p. 83. Cabe destacar que recientemente esta cifra se ha vuelto a poner en tela de juicio, ya que en esta expedición, según los libros de Actas del cabildo de La Coruña fueron realmente 1.638 los milicianos embarcados, no siendo todos casados. SAAVEDRA VÁZQUEZ, María del Carmen: Galicia en el Camino de Flandes, Coruña, 1996, p. 187.

7 SAAVEDRA VÁZQUEZ, María del Carmen: La Coruña durante el reinado de Felipe II, La Coruña, 1989, p. 147 y Galicia en el Camino de Flandes, La Coruña, 1996, pp. 157-158. 
que en Galicia tenía siempre un mayor alcance el reclutamiento intermediario. En las plantillas de reclutamiento realizadas por el Consejo de Guerra en 1604, ninguna de las 46 compañías que se pensaban formar realizaría su recluta en Galicia, ni en la cornisa cantábrica, pese a que algunos capitanes reclutarían incluso en Navarra, Aragón, Valencia y Cataluña. Pero este fenómeno no parece puntual, ya que vuelve a repetirse al año siguiente y en 1624 y 1625 , pese a que en esas últimas fechas Galicia sea un destino de parte de las reclutas que se realizarían en otras partes ${ }^{8}$. Este hecho significa que a Galicia acudirán pocos capitanes a reclutar hombres comisionados desde el Consejo de Guerra, por lo que el reclutamiento administrativo apenas será relevante en el reino, siendo un fenómeno más bien puntual hasta bien entrado el siglo XVII.

En Galicia, como bien ha investigado el profesor Thompson, el reclutamiento fue gestionado a través de intermediarios, sobre todo nativos de prominentes familias que se encargaban de conseguir el apoyo local, y el de sus amigos y parientes que se alistaban en las compañías que reclutaban. De esta manera muchos de los encargados de realizar reclutas en el reino serán personas oriundas elegidas directamente por el Consejo de Guerra, aunque muchas no cumplieran con los requisitos mínimos para ser oficiales, ya que éstos eran los únicos que podían llevar a cabo el reclutamiento con éxito. En el reino, como bien afirmaba uno de estos reclutadores en 1607, la cédula real no bastaba para conseguir el buen logro de un reclutamiento, debido a que los reclutas no estaban asegurados sin las acciones de los notables de la zona. Sin la colaboración de estos intermediarios naturales del reino, el reclutamiento realizado por forasteros solía topar con múltiples dificultades, pero sobre todo con la falta de voluntarios en las ciudades del reino?.

Es difícil llegar a saber con certeza el motivo de la escasa presencia reclutadora oficial en el reino, pero muy posiblemente la respuesta estaba bien lejos de la falta de poder del rey, sino que era más bien un problema coyuntural: la falta de voluntarios. El reclutamiento administrativo realizado por la Corona, y que nutria las filas de los popularizados Tercios, se basaba en el reclutamiento de voluntarios en las ciudades, concentrándose los esfuerzos de los reclutadores en las ciudades y villas más importantes y pobladas, en donde se podrían encontrar más voluntarios. El reclutamiento de voluntarios era una modalidad de reclutamiento eminentemente urbana, ya que necesitaba grandes núcleos de población en donde hubiera una importante mano de obra desempleada, jóvenes con ganas de ver mundo o personas que quisieran abandonar

8 Planificación y patentes de reclutamiento. Archivo General de Simancas (en adelante A.G.S.) Libro Reg. del Consejo de Guerra 96 f. 1-7 y ss.

9 THOMPSON, I.A.A.: Guerra y decadencia. Gobierno y administración en la España de los Austrias, 1560-1620, Barcelona, 1981, p. 148. 
sus quehaceres en pos de una vida mejor, o simplemente como vía de huida, ya fuera de un severo padre, de la servidumbre o de un triste oficio como aprendiz gremial. Los grandes núcleos de población, además, eran focos de atracción de emigración, lo que terminará haciendo de ellos una verdadera cuna del reclutamiento voluntario.

Pero en Galicia, al igual que en la cornisa cantábrica y León, los parámetros esenciales que hacían que las ciudades fueran el centro del reclutamiento de voluntarios no se cumplían. Por un lado el mundo urbano gallego era muy diferente al del resto de Castilla. Las principales ciudades y villas gallegas adolecieron durante los siglos XVI y XVII una continua falta de entidad poblacional, a lo que contribuía el prototipo de extensión espacial de la población gallega. Muy pocas ciudades se transformaron durante ese tiempo en importantes y activos focos de atracción de excedentes poblaciones de todo el reino, sino que los habitantes del mundo rural cercano prefirieron emigrar a Castilla o Andalucía, ya fuera estacionalmente, con motivo de la siega, o definitivamente. Durante el siglo XVII las ciudades gallegas crecieron se recuperaron con respecto al siglo anterior, pero en ellas sus gentes se dedicaron a lo mismo que sus antepasados, sin crearse en ellas unos niveles altos de mano de obra sobrante ${ }^{10}$. Esto suponía que los emigrantes gallegos preferían ir a otros lugares a ganarse la vida, por lo que en las ciudades gallegas no existía una excesiva población desocupada que pudiera estar tentada a alistarse en el ejército sin otros alicientes que sólo el dinero ofrecido.

Aunque la emigración por esas fechas era abundante en Galicia, eran pocos los que optaba directamente por la vida militar y se alistaban en las compañías que se reclutaban en el reino. Esto contrasta con el hecho de que en las levas realizadas en el resto del reino de Castilla -sobre todo en la meseta norte y Andalucía-, un buen número de los reclutados eran emigrantes gallegos. Una parte de estos se alistaban voluntarios, intentado encontrar así nuevas opciones para salir de la pobreza y encontrar un futuro más prometedor que el de ser la clase baja de las ciudades castellanas, mientras que otros eran aplicados a las levas por las autoridades locales por ociosos o vagabundos.

Un buen ejemplo de esta irrupción de soldados gallegos que se alistaban en las compañías que se reclutaban voluntariamente en Castilla lo tenemos especialmente en Valladolid. La capital vallisoletana era un punto clave dentro del reclutamiento voluntario que se realizaba en la meseta norte. La ciudad era un centro de atracción de emigrantes de otras zonas, y muy especialmente jóvenes trabajadores del norte peninsular. Desde el siglo XVI a la ciudad llegaban numerosos originarios de todo

10 La población gallega que vivía a finales del siglo XVIII en municipios de más de 2.000 almas era solamente el 7\% del total, aunque en fechas anteriores era mucho inferior. EIRAS ROEL, Antonio: "Una primera aproximación a la estructura demográfica urbana de Galicia a través del Censo de 1787”, en VILLARES, R. (coord.), La ciudad y el mundo urbano en la historia de Galicia, Santiago, 1988, pp. 155-179. 
el norte peninsular, emigrantes en busca de trabajo, pero también mendicantes que en muchos casos colapsaban las cofradías vallisoletanas en busca de limosnas o asistencia. También muchos procedentes de las montañas de León, Galicia y Asturias llegaban a la ciudad para trabajar como aprendices o trabajadores sin cualificación ${ }^{11}$. En la recluta de la compañía del capitán don Juan de Echandia, formada en Valladolid durante 1668 , prácticamente un $14 \%$ de los alistados eran jóvenes gallegos que no pasaban de los 28 años. Sujetos que seguramente habían llegado a la ciudad hacia poco y no encontraban un trabajo, por lo que las primas de enganche y los socorros diarios con los que poder comer habrían tentado a muchos a alistarse voluntariamente, especialmente en invierno, cuando el trabajo escaseaba en la ciudad y los capitanes reclutadores multiplicaban sus esfuerzos ${ }^{12}$.

En ocasiones, el material encontrado en los archivos sobre el reclutamiento nos brinda una información muy útil, pero difícil de encontrar. Esta es la documentación de los listados de las compañías reclutadas, en los que se hace referencia al nombre del recluta, su edad, su descripción física, su naturaleza (procedencia geográfica) y su parentesco (nombre de su padre). Gracias a esta información de múltiples compañías, hemos podido saber el origen de más de 4.000 reclutas alistados fundamentalmente en las dos Castillas y Andalucía, aunque también en otras partes. En todos estos listados, por norma, encontramos a algún sujeto gallego, incluso en zonas donde parece incluso extraña su presencia.

La tipología de reclutamiento influirá mucho en la presencia de gallegos en las reclutas, ya que procedimientos como el alistamiento a cargo de los vecindarios centraba sus acciones sobre los habitantes concretos de amplias zonas, por lo que en conjunto estos reclutamientos van a darnos un nivel bajo de soldados gallegos entre sus filas, de entre el 1\% al 3\%, algo bastante normal, pero aún así relevante. Otros procedimientos como los repartimientos igualmente estaban basados en el reclutamiento de cupos entre los municipios de una zona, por lo que en muchos casos eran vecinos de estos lugares los que salían a servir en el ejército, aunque también habitualmente se enviaban todos los hombres forasteros que las autoridades locales encontraban en la zona. Así en 1676 distintos municipios de Tierra de Campos entregaron 22 sujetos gallegos a cargo de la leva que se les pidió, cifra que correspondía a casi el $21 \%$ del total de hombres entregados. Estos sujetos en su mayoría eran jóvenes gallegos que comenzaban a llegar a la zona para realizar la siega, aunque también había personas que ya estaban avecindadas

11 BENNASSAR, Bartolomé: en V.V.A.A., Valladolid corazón del mundo hispánico. Siglo XVI, Valladolid, 1981, pp. 82-86 y 116.

12 Traslado de la muestra y marcha de la compañía de infantería española del capitán don Juan de Echandia, Valladolid, 3 de abril 1668. A.G.S. Guerra Antigua (en adelante A.G.S. G.A. Leg. 2.190). 
en muchas localidades, pero que por ser forasteros fueron elegidos por las autoridades locales para ir a servir en el ejército por los vecinos del pueblo ${ }^{13}$.

Dentro del conjunto, tiene especial relevancia la proporción de gallegos que se alistan voluntarios en las compañías, tanto en las realizadas directamente por capitanes comisionados por la Corona, como los alistados en las compañías reclutadas a costa de particulares o por las mismas ciudades, aunque éstas últimas generalmente intentaban captar en sus compañías al mayor número posible de sus vecinos. Esto supone que la mayor parte de los gallegos alistados en todas estas compañías eran voluntarios, lo que reflejaba no tanto su espíritu o vocación militar, sino su necesidad como emigrantes en el mundo urbano castellano.

Pero aunque fuera notable la presencia de gallegos dentro del alistamiento voluntario en Castilla, todas las levas voluntarias que se produjeron en Galicia durante la segunda mitad del siglo XVII tuvieron unos pésimos resultados. De hecho, a pesar de que desde 1648 se había intentado reclutar voluntarios en el reino, en contadas ocasiones estas reclutas llegaban a alistar a más que un puñado de soldados, teniendo que usarse otros sistemas de reclutamiento. En 1668, de las ocho compañías que se mandaron reclutar en las ciudades y villas del reino para Flandes, sólo cuatro realmente estaban compuestas por voluntarios, ya que el resto de los hombres eran forzados y soldados aplicados de los tercios pilones ${ }^{14}$. Durante ese tiempo el principal problema era la actuación militar de los gallegos en la frontera, por lo que era difícil conseguir una recluta exclusivamente de voluntarios. Desde el primer momento se sabía la dificultad de la recluta, algo que el Condestable de Castilla, a la sazón gobernador del reino, alegaba al "horror que los naturales tienen a la guerra". Pero el Condestable era mucho más preciso, ya que afirmaba que "el problema es que no habra voluntarios, porque todos los soldados que sirven en estos tercios son forzados, tanto como si estubieran en galeras y ni con castigos ni diligencias humanas se les puede obligar a que subsistan 8 dias en la frontera"'15. Se llegó a pensar desde el Consejo de Guerra el hecho de proporcionar unos fuertes socorros diarios a los nuevos reclutas de hasta 4 reales, para intentar que muchos se alistaran por "la codicia de goçar de estos socorros", pero lo cierto es que los ministros de Madrid se equivocaban. Desde Galicia se sabía que ni dando 50 reales a cada soldado se conseguiría que salieran los suficientes voluntarios ${ }^{16}$.

13 Testimonio de las diligencias que se han hecho por parte del Corregidor de León con don Gaspar de Mondragón..., Valladolid 19 de marzo 1676. A.G.S. G.A. Leg. 2.369.

14 Informe del veedor del reino de Galicia, 22 de noviembre 1681. A.G.S. G.A. Leg. 2.581.

15 Carta del Condestable de Galicia, Gobernador del Reino de Galicia, 1 de octubre 1667. Consejo de Guerra, 10 de octubre 1667. A.G.S. G.A. Leg. 2.135.

16 Carta de don Diego Sarmiento, 11 de septiembre 1667. Consejo de Guerra, 14 de septiembre 1667. A.G.S. G.A. Leg. 2.136. Carta del Consejo de Guerra al Condestable de Castilla, Capitán General de Galicia, 29 de septiembre 1667. A.G.S. Libro Reg. del Consejo de Guerra 307 f. 54 . Cartas del Condestable de Galicia, Gobernador del Reino de Galicia, 1 y 21 de octubre 1667. A.G.S. Estado Leg. 2.686. 
Tabla I: Soldados gallegos reclutados en las levas realizadas en otros puntos de la península:

\begin{tabular}{|c|c|c|c|c|c|c|}
\hline Año & $\begin{array}{l}\text { Lugares de Re- } \\
\text { clutamiento }\end{array}$ & $\begin{array}{l}\text { Plazas recluta- } \\
\text { das que conoce- } \\
\text { mos origen }\end{array}$ & $\begin{array}{l}\text { Número de } \\
\text { soldados } \\
\text { Gallegos }\end{array}$ & $\begin{array}{l}\text { Por ciento } \\
\text { de los solda- } \\
\text { dos gallegos }\end{array}$ & Tipo de leva & Destino \\
\hline 1650 & Palencia & 14 & 1 & $7,14 \%$ & Voluntarios & Cataluña \\
\hline 1651 & Ávila & 30 & 2 & $6,66 \%$ & Voluntarios & Armada \\
\hline 1659 & Ávila & 79 & 24 & $30,38 \%$ & Voluntarios & Extremadura \\
\hline 1668 & Valladolid & 80 & 11 & $13,75 \%$ & Voluntarios & Flandes \\
\hline 1676 & $\begin{array}{l}\text { Zamora, León y } \\
\text { Valladolid }\end{array}$ & 105 & 22 & $20,95 \%$ & $\begin{array}{l}\text { Voluntarios y reparti- } \\
\text { miento }\end{array}$ & Cataluña \\
\hline 1678 & $\begin{array}{l}\text { Madrid, Toledo y } \\
\text { Valladolid }\end{array}$ & 80 & 7 & $8,75 \%$ & $\begin{array}{l}\text { Voluntarios y reparti- } \\
\text { miento }\end{array}$ & Cataluña \\
\hline 1650 & Toledo & 59 & 4 & $6,77 \%$ & Repartimiento & Cataluña \\
\hline 1651 & Almagro & 127 & 1 & $0,78 \%$ & Repartimiento & Cataluña \\
\hline 1653 & Guadalajara & 75 & 6 & $8 \%$ & Repartimiento & Cataluña \\
\hline $\begin{array}{l}1648- \\
1691\end{array}$ & $\begin{array}{l}\text { Provincia de } \\
\text { Álava }\end{array}$ & 1.677 & 149 & $8,88 \%$ & $\begin{array}{l}\text { Servicio de la Pro- } \\
\text { vincia }\end{array}$ & $\begin{array}{l}\text { Cataluña, } \\
\text { Flandes y la } \\
\text { Armada } \\
\end{array}$ \\
\hline 1694 & Cuenca & 630 & 15 & $2,38 \%$ & $\begin{array}{l}\text { A cargo de los vecin- } \\
\text { darios }\end{array}$ & Cataluña \\
\hline 1694 & $\begin{array}{l}\text { Molina de Ara- } \\
\text { gón }\end{array}$ & 165 & 2 & $1,21 \%$ & $\begin{array}{l}\text { A cargo de los vecin- } \\
\text { darios }\end{array}$ & Cataluña \\
\hline 1695 & Toledo & 520 & 14 & $2,69 \%$ & $\begin{array}{l}\text { A cargo de los vecin- } \\
\text { darios }\end{array}$ & Cataluña \\
\hline 1695 & $\begin{array}{l}\text { Principado de } \\
\text { Asturias }\end{array}$ & 262 & 8 & $3,05 \%$ & $\begin{array}{l}\text { A cargo de los vecin- } \\
\text { darios }\end{array}$ & Cataluña \\
\hline 1696 & Toledo & 81 & 1 & $1,23 \%$ & $\begin{array}{l}\text { A cargo de los vecin- } \\
\text { darios }\end{array}$ & Cataluña \\
\hline 1690 & Baeza & 84 & 3 & $3,57 \%$ & $\begin{array}{l}\text { Reclutamiento a } \\
\text { cargo de la ciudad }\end{array}$ & Cataluña \\
\hline 1692 & Córdoba & 16 & 1 & $6,25 \%$ & $\begin{array}{l}\text { Reclutamiento a } \\
\text { cargo de la ciudad }\end{array}$ & Cataluña \\
\hline 1692 & Écija & 30 & 7 & $23,33 \%$ & $\begin{array}{l}\text { Reclutamiento a } \\
\text { cargo de la ciudad }\end{array}$ & Cataluña \\
\hline 1677 & Aragón & 66 & 5 & $7,57 \%$ & $\begin{array}{l}\text { Compañía reclutada a } \\
\text { costa de su capitán }\end{array}$ & Cataluña \\
\hline \multirow[t]{2}{*}{1690} & Córdoba & 38 & 6 & $15,78 \%$ & $\begin{array}{l}\text { Compañía reclutada a } \\
\text { costa de su capitán }\end{array}$ & Cádiz \\
\hline & Total: & 4.218 & 289 & $6,85 \%$ & & \\
\hline
\end{tabular}

Fuente: A.G.S. G.A. Leg. 1.773, 1.950, 2.190, 2.369, 2.397, 2.408, 2.849, 2.886, 2.905, 2.909, 2.948, 2.967, 2.995, 3.002, 2.011 y 3.323. A.G.S. Contaduría Mayor de Cuentas 3 a época Leg. 740 y 1.453. A.G.S. Contaduría del Sueldo 2a Serie Leg. 410. Actas de las Juntas Generales de Álava, 1648-1691. 
Pero en esa ocasión no sólo parecía difícil que los propios naturales se alistaran como soldados, sino que también hubo notables problemas para encontrar capitanes naturales del reino que quisieran hacerse cargo de la recluta. De las primeras cuatro compañías proveídas solamente una de ellas recayó en un gallego, ya que ningún otro había mostrado interés por la patente. Ante esta situación la Corona determinó que para las restantes compañías que faltaban de proveer se nombrarán a cuatro sujetos gallegos de entre los soldados más experimentados del ejército de la frontera, intentando fomentar así el enganche al nombrar a oriundos del reino como oficiales. Pero el método tampoco dio los resultados esperados, y el reclutamiento efectuado en las siete ciudades del reino y la villa de Pontevedra apenas dio para formar la mitad de las compañías, por lo que el resto debieron ser completadas con forzados ${ }^{17}$.

En la década siguiente el reclutamiento del tercio del Conde de Amarante, en 1674, también fue complicado. Inicialmente la Corona intentó que la nueva unidad se completara reclutando al menos 1.000 soldados voluntarios en 11 compañías formadas con oficiales naturales del reino, para lo que se dieron al gobernador de Galicia las suficientes patentes en blanco. Estas patentes se pensaban entregar a "cavalleros naturales de esse reyno que tengan séquito y autoridad, y puedan por si y por sus deudos y amigos aumentar esta leva, para que sus compañias vayan muy numerosas; $y$ en soldados que ayan servido en los exercitos "'18. Pero aunque se pensó que la intervención del Maestre de Campo y los diferentes oficiales sería suficiente para captar voluntarios, al ser estos personas naturales del reino, lo cierto es que no se consiguió lo pretendido, por lo que sólo fue posible formar el tercio gracias a las diversas aportaciones realizadas por las diferentes provincias, que contribuyeron a través de un repartimiento de soldados forzosos con cerca de 1.100 soldados, reclutándose solamente 46 soldados voluntarios según las certificaciones oficiales ${ }^{19}$.

En 1675 se volvió a intentar realizar una leva voluntaria en el reino, nombrándose para el mando del nuevo tercio a otro natural, el Marqués de Arcos y Tenorio y Conde de Crecente. Pero tras arbolar 12 banderas en todo el reino durante cerca de 11 meses, apenas se pudo conseguir enviar a Flandes 353 plazas en cuatro compañías,

17 Carta del Consejo de Guerra al Condestable de Castilla, Capitán General de Galicia, 18 de octubre y 10 de diciembre 1667. A.G.S. Libro Reg. del Consejo de Guerra 307 f. 62 y 104. Consejo de Guerra, 7 de diciembre 1667. A.G.S. G.A. Leg. 2.132.

18 Carta del Consejo de Guerra al Conde de Aranda, Gobernador y Capitán general de Galicia, 6 de diciembre 1673. A.G.S. Libro Reg. del Consejo de Guerra 325 f. 80 . Carta del Conde de Aranda, Gobernador y Capitán general de Galicia, 9 de enero 1674. A.G.S. G.A. Leg. 2.242. Resolución del Consejo de Guerra sobre las pretensiones del Conde de Amarante, 16 de septiembre 1661. A.G.S. G.A. Leg. 1.995. Relación de Servicios del Maestro de Campo don García Ozores López de Lemos, Conde de Amarante, marzo 1680. A.G.S. G.A. Servicios Militares Leg. 25 f. 27.

19 Consejo de Guerra, 6 de abril 1674, con carta inclusa del Conde de Aranda. Informe del veedor del reino de Galicia, 22 de noviembre 1681. A.G.S. G.A. Leg. 2.301 y 2.581. 
Tabla II: Soldados reclutados en la leva voluntaria hasta 6 de octubre 1675:

\begin{tabular}{|c|c|c|c|}
\hline $\begin{array}{l}\text { Lugares donde se arbola- } \\
\text { ron banderas }\end{array}$ & $\begin{array}{c}\text { Soldados entregados en el } \\
\text { castillo de San Antón (Coruña) }\end{array}$ & $\begin{array}{l}\text { Soldados que estaban } \\
\text { aún en las ciudades }\end{array}$ & $\begin{array}{l}\text { Población aproximada de } \\
\text { las ciudades en } 1675^{*}\end{array}$ \\
\hline Santiago & 38 & & 10.000 \\
\hline Coruña y Betanzos & 27 & 3 & 1.500 y 1.000 \\
\hline Lugo & 8 & & 1.000 \\
\hline Orense & 54 & & 1.000 \\
\hline Tuy & 5 & & 1.000 \\
\hline Mondoñedo & 4 & & 400 \\
\hline Ribadavia & 16 & 1 & 400 \\
\hline Pontevedra & 23 & & 1.500 \\
\hline Vigo & 4 & 1 & 500 \\
\hline Ribadeo & 3 & & 350 \\
\hline \multirow[t]{2}{*}{ Monterrey y Monforte } & 17 & & 100 y 800 \\
\hline & 199 & 5 & \\
\hline $\begin{array}{l}\text { Entregados a cuenta del } \\
\text { Marqués (Tuy y Orense) }\end{array}$ & 43 & 2 & \\
\hline Condenados & 16 & & \\
\hline \multirow[t]{2}{*}{ Total } & 258 & 7 & \\
\hline & & 265 & \\
\hline
\end{tabular}

Fuente: A.G.S. G.A. Leg. 2.321.

(Nota*: Cifras redondeadas y de carácter orientativo que se incluyen por coincidir con el año de la leva y a falta de un recuento fidedigno. Según MÉNDEZ SILVA, Rodrigo: Población General de España, segunda edición, Madrid, 1675).

ocasionando unos gastos enormes en el reino, debidos al alojamiento de los mandos y soldados ${ }^{20}$. El problema desde el principio había sido una mediocre gestión del reclutamiento, llegándose a producirse distintos altercados entre el Maestre de Campo de la nueva unidad y el gobernador del reino. Los voluntarios escaseaban, pese a la presencia de numerosas banderas arboladas en las principales ciudades y villas del reino. A esto se unía el hecho de que la recluta erróneamente había comenzado en un época algo tardía para poder cosechar los tan ansiados voluntarios, ya que todos los años desde el mes de abril gran número de gallegos partían para Castilla a realizar la siega, con lo que muy pocos hombres en esos meses podían ser tentados a alistarse con el dinero que se ofrecía ${ }^{21}$.

20 Informe del veedor del reino de Galicia, 22 de noviembre 1681. A.G.S. G.A. Leg. 2.581. Tanteo y relación con cargo y data del dinero que de orden de su Majestad se ha remitido y entrado en poder a distribución del señor Conde de Aranda para los gastos de las levas de infantería, 13 de septiembre 1676. Carta del conde de Aranda, Gobernador del reino de Galicia, 23 de agosto 1676. A.G.S. G.A. Leg. 2.370 y 2.371 .

21 Cartas del Consejo de Guerra al Conde de Aranda, Capitán general de Galicia, 29 de junio, 15 y 31 de julio, 9 de septiembre 1675. A.G.S. Libro Reg. del Consejo de Guerra 329 f. 135v, 146v, 151v y 177. Consejo de Guerra, 31 de mayo y 17 de junio 1675. A.G.S. G.A. Leg. 2.323. 
En octubre de 1675 se hizo una muestra de los soldados que había en las 11 banderas arboladas en las distintas ciudades y villas del reino, además de los que estaban condenados y los hombres que había reclutado a su costa el Maestre de Campo. Tras casi siete meses de reclutamientos apenas se habían reunido 250 hombres, habiéndose gastado ya en los socorros de los oficiales y soldados de esta leva 30.000 ducados. El problema era que en las 11 banderas arboladas en las principales ciudades y villas del reino apenas se habían podido reclutar poco más de 200 hombres, habiendo aportado el Maestre de Campo cerca de otros 50. Con un balance reclutador tan negativo, tras tantos meses, estaba claro que cualquier leva voluntaria estaba condenada al fracaso. De hecho solamente la ciudad de Orense había proporcionado un número mediocre de voluntarios, mientras que en otras importantes villas del reino apenas se habían reclutado 4 o 5 hombres, más o menos uno por cada mes que había permanecido la bandera arbolada ${ }^{22}$.

Pero la Corona no se rindió ante la imposibilidad de conseguir voluntarios, por lo que en muchas ocasiones no aceptó que se retirasen las banderas que estaban arboladas en las ciudades, pese a las molestias y gastos que producían al reino, aludiendo para ello estas palabras: "por que si atendiendo ala lentitud con que se levanta la gente voluntaria se huviese de sobreseer en las levas no abria forma de juntar gente, ni de recrutar los exercitos "'23. Pero pese a la perseverancia de la Corona las cosas tampoco cambiaron en la década siguiente, en la que la Corona siguió intentado captar voluntarios en el reino. En 1680 el Conde de Grajal sólo logro alistar 350 voluntarios después permanecer reclutando en el reino más de cinco meses ${ }^{24}$. Pero tras el nuevo fracaso, que no pudo ser compensado con la realización de algún servicio por el reino, como había ocurrido en otras ocasiones, la Corona dejó de intentar reclutar tercios enteros de manera voluntaria en el reino. Estaba claro que aunque siempre se optó por elegir Maestres de Campo naturales de Galicia, o con importantes vínculos con el reino, además de oficiales naturales, ni siquiera esto solía ser suficiente ante la falta de voluntarios.

22 Cartas del Conde de Aranda, Gobernador del reino de Galicia, 6, 13 y 20 de octubre 1675. A.G.S. G.A. Leg. 2.321. Consejo de Guerra, 14 de octubre y 29 de noviembre 1675. A.G.S. G.A. Leg. 2.325 .

23 Carta del Consejo de Guerra al Conde de Aranda, Capitán general de Galicia, 20 de septiembre 1675. A.G.S. Libro Reg. del Consejo de Guerra 329 f. 212.

24 Carta del Consejo de Guerra al Marqués de Villafiel, Gobernador del reino de Galicia, 8 de julio y 26 de agosto 1680. A.G.S. Libro Reg. del Consejo de Guerra 365. Carta del Marqués de Villafiel, Gobernador del reino de Galicia, 22 de septiembre 1680. Consejo de Guerra, 7 de octubre 1680. Relación de los oficiales de primera plana mayor del tercio del Maestre de campo Conde de Grajal, Coruña, 17 de septiembre 1680. A.G.S. G.A. Leg. 2.479. Carta del secretario don Crispín Botello, Bruselas 4 de diciembre 1680. A.G.S. Estado Leg. 4.102. 
Solamente en 1683 encontramos una excepción a este cambio de política. En ese año se pudieron reclutar en el reino dos compañías voluntarias por dos capitanes llegados del ejército de Flandes, sin que los oficiales necesitaran demasiados meses para completar la leva. El reclutamiento se efectuó en las ciudades de Santiago y Orense, que parecían los lugares más propicios para el reclutamiento voluntario. Pero está claro que el éxito del reclutamiento estaba en que hacía años que no se realizaban otras reclutas en el reino y que apenas salieron para Flandes 200 soldados voluntarios ${ }^{25}$.

\section{b) El reclutamiento realizado mediante la intermediación de la nobleza y el clero gallego}

Desde siempre la Corona se había enfrentado en Galicia al problema de falta de voluntarios. Por este motivo siempre intentó encontrar intermediarios que facilitasen el reclutamiento en el reino, por lo repetidamente durante el siglo XVI había acudido a la nobleza. Será la gran nobleza del reino la que aporte soldados reclutados entre sus vasallos para operaciones militares tan importantes como la Armada Invencible, debido a que la intervención de éstos facilitaba y agilizaba el reclutamiento ${ }^{26}$. Aunque ya en el siglo XVII esta clase de aportaciones empezarán a quedar algo obsoletas en buena parte del territorio peninsular, algo contrastado con el fracaso de la movilización nobiliaria planteada por Olivares ${ }^{27}$, aún en Galicia los grandes señores aportarán hombres al conjunto de la monarquía al igual que la iglesia, propietaria de grandes espacios en el reino.

Una de las fórmulas planteadas siempre que se necesitaba una importante recluta en Galicia era la intervención de la nobleza, la iglesia y comunidades religiosas del reino, para que reclutasen hombres y formasen algunas compañías a su propia costa. Esto era algo que ya se había realizado con éxito en 1631. En ese año gracias a la intervención de los prelados y títulos del reino, que sirvieron aportando distintas compañías, se embarcaron más de 1.200 hombres para los Países Bajos ${ }^{28}$. Esta misma

25 Consejo de Guerra, 1 de septiembre y 22 de octubre 1683. A.G.S. G.A. Leg. 2.580 y 2.583. Cartas del Marqués de Grana, Gobernador de los Países Bajos, 8 de septiembre y 3 de noviembre 1683. Relación inclusa de la gente que se ha levantado en Galicia, Burgos y Santo Domingo de la Calzada. A.G.S. Estado Leg. 3.873.

26 SAAVEDRA VÁZQUEZ, María del Carmen: La Coruña durante el reinado de Felipe II, La Coruña, 1989, p. 142.

27 DOMINGUEZ ORTIZ, Antonio: “La Movilización de la nobleza castellana en 1640”, en Anuario de Historia del Derecho Español $N^{\circ} 25$, Madrid, 1955, p. 799-823.

28 Carta de don Diego Sarmiento, 11 de septiembre 1667. A.G.S. G.A. Leg. 2.136. SAAVEDRA VÁZQUEZ, María del Carmen: Galicia en el Camino de Flandes, Coruña, 1996, pp. 157-160. ALCALÁZAMORA Y QUEIPO DE LLANO, José: España, Flandes y el Mar del Norte (1618-1639). La última ofensiva europea de los Austrias madrileños, Barcelona, 1975, pp. 331-334. 
colaboración se pidió de nuevo en 1653, solicitando 900 soldados para Flandes al Arzobispado de Santiago, las dos principales órdenes monásticas del reino -San Benito y San Bernardo (Císter) - y a los Condes de Altamira y Lemos, ya que sus tierras estaban lejos de la frontera y no colaboraban tan activamente al sostenimiento económico y militar de la frontera como lo hacían otros señores ${ }^{29}$. Pero finalmente el reclutamiento no tuvo efecto, ya que apenas fueron entregados algunos hombres por el Conde de Altamira, que ya en anteriores ocasiones se había mostrado sumamente colaborador en el reclutamiento para Flandes. El problema, y el fracaso del reclutamiento, estaban motivado por la activa participación del reino en la defensa de la frontera, por lo que difícilmente se podían sacar hombres para Flandes ${ }^{30}$.

Pero a finales de 1667 las cosas cambiarán tras la invasión francesa de los Países Bajos que conllevará el estallido de la llamada Guerra de Devolución. En esos momentos críticos para la regencia de Carlos II la Corona solicitó la aportación de una compañía de 100 hombres a los grandes nobles con posesiones en Galicia -en concreto a los condes de Lemos, Rivadavia y Altamira-, además de una compañía al arzobispado de Santiago y otras dos a las órdenes monásticas de San Benito y San Bernardo. Mediante estos servicios se pretendían enviar un buen número de hombres a Flandes, pero la contestación de la nobleza fue escasa y ninguna casa noble se comprometió a reclutar hombres, alegando la cantidad de esfuerzos que habían soportado en la reciente guerra contra Portugal. La iglesia, en cambio, se mostró más colaboradora, aportando las tres compañías requeridas, que se formaron al quintar el número de hombres pedidos entre los lugares jurisdiccionales de la iglesia. Todos los gastos del reclutamiento se pagaron también a su cargo, pudiendo la iglesia gallega elegir los oficiales de las compañías que se formarían de sus vasallos para facilitar así el servicio ${ }^{31}$.

En otras dos ocasiones durante el resto del reinado de Carlos II la monarquía volvió a pedir la colaboración del clero gallego, aunque las peticiones a la alta nobleza no volvieron a sucederse ante su continuo incumplimiento. En especial estas demandas se realizaron en momentos de apuro, ayudando así a completar las aportaciones que de hombres que se necesitaban. Así en 1684, con el estallido de una nueva guerra en Flandes, la Guerra de Luxemburgo, se pidieron hombres a las órdenes monásticas del reino (San Benito y Císter) y los diferentes arzobispados, obispados y cabildos

29 Cartas de justicia a diferentes personas para la leva en Galicia para Flandes, 1 de abril 1653. A.G.S. Libro Reg. del Consejo de Guerra 234 f. 173.

30 Carta del Consejo de Guerra a don Juan Pardo de Figueroa sobre la remisión de las reclutas, 11 de junio 1653. A.G.S. Libro Reg. del Consejo de Guerra 234 f. 198v. Junta de Guerra, 24 de mayo y 28 de junio 1653. A.G.S. G.A. Leg. 1.825.

31 Cartas del Consejo de Guerra al Condestable de Castilla, Capitán General de Galicia, 20 de octubre y 15 de noviembre 1667. A.G.S. Libro Reg. del Consejo de Guerra 307 f. 65 y 89v. Carta de don Diego Sarmiento, 11 de septiembre 1667. A.G.S. G.A. Leg. 2.136. 
catedralicios del reino. Pero la contestación no fue unánime. Mientras que las órdenes monásticas entregaron una compañía de 100 hombres cada una, solamente el Arzobispado y el Cabildo de Santiago cumplieron con la petición de la Corona y entregaron sendas compañías de 100 hombres. Otros obispados como los de Lugo y Mondoñedo, atendiendo a sus menores medios y población, se comprometieron a ayudar al reclutamiento aportado dinero ${ }^{32}$. En 1692 se volvió a formular una petición parecida, y aunque se pidió al clero gallego un total de 875 hombres, solamente se pudo conseguir que aportasen 200 en dos compañías, excusándose muchos a participar en la recluta, entregando otros solamente dinero para financiar el reclutamiento ${ }^{33}$.

Gracias a distintos informes realizados tras las aportaciones de los monasterios de San Benito y el Císter en Galicia, sabemos con bastante exactitud el método de reclutamiento empleado para la formación de las compañías aportadas por el clero. El sistema era sumamente sencillo, al repartirse la cantidad requerida por la Corona entre los distintos monasterios que las diferentes órdenes tenían en Galicia, según su población. Esto significaba una recluta forzosa en toda regla, al ser encaminados a Flandes toda una serie de personas que vivían y cultivaban las tierras monásticas. Los monasterios con menos poder y población igualmente contribuían al conjunto con dinero para poder pagar los gastos del reclutamiento, los vestidos de munición y espadas de los soldados. Esta misma fórmula sería igualmente utilizada por el Arzobispado de Santiago y los diferentes cabildos y obispados del reino que se comprometieron a aportar hombres durante el reinado de Carlos $\mathrm{II}^{34}$.

\section{c) Las levas forzosas y el reclutamiento de los tercios pilones}

Debido a la falta de voluntarios, en el reino de Galicia se tenían que usar, para poder reclutar hombres, fórmulas distintas a las empleadas en el resto de Castilla, ya fuera para servir en el exterior o en la propia frontera en la guerra contra Portugal. De hecho el propio reino, a través de sus representantes, equiparaba el reclutamiento

32 Cartas del Consejo de Guerra al Duque de Uceda, Gobernador del reino de Galicia, 25 de abril y 7 de junio 1684. A.G.S. Libro Reg. del Consejo de Guerra 365 f. 66 y 86v. Consejo de Guerra, 18 de febrero 1684. Consejo de Guerra, 15 de marzo y 25 de mayo 1684. A.G.S. G.A Leg. 2.612.

33 Cartas del Conde de Puñoenrostro, Gobernador del reino de Galicia, 20 de julio y 12 de agosto 1691 y 8 de marzo 1692. Consejo de Estado, 9 de julio 1691. A.G.S. Estado Leg. 4.171.

34 Lista de la gente con que sirvieron las religiones de San Benito y San Bernardo en este reino de Galicia el año de 1668, puestos a su costa en la ciudad de La Coruña con vestidos y espadas. A.G.S. G.A. Leg. 2.284. Para poder localizar muchos de estos monasterios he recurrido a MORALES, Ambrosio: Relación del viaje que Ambrosio Morales, Cronista de S.M., hizo por su mandato el año 1572 en Galicia, Asturias y León, Madrid, 1765. Segunda edición de 1792. 
Tabla III: Repartimiento efectuado en 1668 en los diferentes monasterios de la orden de San Benito y San Bernardo:

\begin{tabular}{|c|c|c|}
\hline Monasterios & Provincia actual (denominación actual) & Soldados \\
\hline \multicolumn{3}{|l|}{ Religión de San Benito: } \\
\hline Monasterio Real de San Martín de Santiago & La Coruña & 20 \\
\hline Monasterio Real de Celanova & Orense & 18 \\
\hline San Esteban de Ribas de Sil & Lugo (San Clodio-Ribas de Sil) & 15 \\
\hline San Julián de Samos & Lugo & 17 \\
\hline San Vicente de Monforte & Lugo & 10 \\
\hline Lorenzana & Lugo (Vilanova- Lourenzá) & 8 \\
\hline San Juan del Poyo & Pontevedra (0 Convento- Poio) & 6 \\
\hline San Salvador de Leriz & Pontevedra (Meis- San Salvador) & 4 \\
\hline San Pedro Tenorio & Pontevedra (Concejo de Cotobade) & 2 \\
\hline Todos: & & 100 \\
\hline \multicolumn{3}{|l|}{ Religión de San Bernardo (Císter): } \\
\hline $\begin{array}{l}\text { Meira, ayudado por el de Peña Morco con } 100 \\
\text { ducados }\end{array}$ & Lugo y enclave no conocido & 8 \\
\hline Monfero & La Coruña (Rebordelo) & 10 \\
\hline Sobrado & La Coruña (Sobrado dos Monxes) & 20 \\
\hline San Clodio & Orense & 12 \\
\hline Osera & Orense (Oseira) & 22 \\
\hline Junquera de Espadan & Orense (Xunqueira de Espadanero) & 4 \\
\hline Montederramo & Orense & 16 \\
\hline $\begin{array}{l}\text { Melón, ayudándole el de Armentera con } 100 \\
\text { ducados, el de } 0 \text { Cebrero con } 50 \text { y Franquera } \\
\text { con } 40\end{array}$ & $\begin{array}{l}\text { Orense (Melón) , Pontevedra (Armenteira y A } \\
\text { Franqueira) y Lugo (0 Cebreiro) }\end{array}$ & 8 \\
\hline Todos: & & 100 \\
\hline
\end{tabular}

Fuente: A.G.S. G.A. Leg. 2.284.

forzoso a través de un repartimiento al voluntariado, alegando que este género de reclutas generaba incluso menos molestias ${ }^{35}$, algo sin duda insólito, al equiparar una recluta voluntaria con una forzosa. Con estas palabras el Consejo de Guerra se hacia eco de este hecho:

“...respecto de que estas ciudades no encuentran incombeniente alguno en executar esta leva sin el nombre de voluntarios, dice el Duque (de Uceda, Gobernador del Reino de Galicia) que siendo este el medio que siempre se ha usado en aquel reino y en cuia execución las mismas ciudades cabezas de provincia han hallado combeniencia y beneficio público, sacando los malentretenidos y que consumen los bastimentos"36.

35 Consejo de Guerra, 21 de enero 1680. A.G.S. G.A. Leg. 2.476.

36 Consejo de Guerra, 18 de febrero 1684. A.G.S. G.A Leg. 2.615. 
La raíz de esto estaba en parte en la propia guerra con Portugal, en la que el reino había servido activamente con muchos soldados, siendo la recluta forzosa en toda regla el medio empleado para la obtención de los elevados contingentes que servían en la frontera. A raíz de la sublevación portuguesa de 1640 se formará en Galicia un ejército, tanto para defender la frontera como para intentar recuperar el país vecino. El ejército creado en Galicia será el segundo en importancia numérica, detrás del ejército de Extremadura, campo de batalla principal en el intento de recuperar Portugal. En los primeros años del enfrentamiento las Juntas del Reino de Galicia se comprometieron a movilizar hasta 16.000 milicianos para proteger la frontera, aunque con el paso del tiempo estos soldados no van a ser suficientes, ni van a tener la necesaria calidad y permanencia para poder ser de utilidad en el frente, ya que en realidad eran muchos menos los que efectivamente llegaban a servir en la frontera. La falta de pagas y de unos alojamientos en condiciones para tantas personas, harán que entre estas tropas no profesionales las enfermedades y deserciones fueran muy elevadas ${ }^{37}$. Muy pronto el propio reino será consciente de la necesidad de establecer un cambio, aportar menos hombres pero de una manera eficaz. Hacia 1649 el ejército de Galicia definitivamente se compondrá por solo 4.000 infantes y 800 caballos, pero todos más o menos fijos y efectivos a raíz de unas mejores pagas y condiciones. Pero si bien estos hombres constituían las dotaciones fijas que permanecían movilizadas todo el año, en el verano, coincidiendo con la campaña militar, las milicias de todos los puntos de Galicia podían ser convocadas en masa para acudir donde fuera necesario ${ }^{38}$.

Pero esta infantería del ejército estaba formada por los llamados tercios de pilones. En ellos servían algunos soldados voluntarios, pero la mayoría de sus componentes eran hombres que habían sido sorteados por las autoridades locales para formar parte del ejército que defendía la frontera, usando como base las pilas bautismales de todas las parroquias que formaban el reino, de ahí su nombre. A cambio de este servicio los soldados cobraban media paga y recibían diariamente pan de munición. Su reemplazo se efectuaba anualmente debido a las deserciones y a la continua falta de soldados. Estos hombres, por tanto, no eran unos simples milicianos y podrían ser considerados unos semiprofesionales, pero no unos soldados profesionales. Aunque la mayoría eran soldados alistados forzosamente, cobraban sueldo del rey, lo que a ojos de la Corona les hacía soldados a todas luces. Con el paso del tiempo estos tercios tenderán a evolucionar en número, sobre todo a partir de la década de

37 CASTILLA SOTO, Josefina y CUBA REGUEIRA, Ana M": "La aportación de Galicia a la Guerra de Secesión de Portugal (1640-1668)", en Espacio, Tiempo y Forma, Serie IV, Ha Moderna, Tomo 9, 1996, Madrid, pp. 234-235. EIRAS ROEL, Antonio: "Las Juntas del Reino de Galicia de 1642 a 1647” en Actas de las Juntas del Reino de Galicia. Tomo V: 1642-1647, Santiago de Compostela, 2001, pp. 10-15.

38 Junta del 19 de diciembre 1649. Documento 15-A. Actas de las Juntas del Reino de Galicia. Tomo VI: 1648-1654, Santiago de Compostela, 1999. 
1650, momento en la que en el frente gallego empieza a haber una mayor actividad militar, más allá de una guerra defensiva. A partir de esas fechas la dotación teórica del ejército de Galicia pasará a 7.500 soldados pilones en siete tercios, aumentándose tres tercios de los cuatro que se habían formado inicialmente en el ejército. Pero muy rápido se deberá establecer una importante reforma ante el incumplimiento de las dotaciones reales de los tercios, quedando estos reducidos a cinco tercios fijos. A partir de 1664 se luchará para la creación de nuevos tercios de pilones para que el componente real del ejército ascendiera a los 10.000 infantes, una cifra que nunca se llegaría a alcanzar, aunque definitivamente se llegarían a crear nueve tercios pilones en el reino hacia 1665, manteniéndose esta aportación hasta el final de la guerra ${ }^{39}$.

Pero a pesar de aumentar el número de tercios, lo cierto es que durante la década de 1660 -la de mayor actividad bélica en el frente gallego-, apenas aumentó el número de soldados pilones en el reino con respecto al pasado. Durante toda esa década la cifra varió bastante poco, entre los 5.000 a 6.000 infantes inicialmente, ascendiendo bastante poco a pesar de la creación de más cuerpos. En cuanto a la caballería gallega que servía en la frontera, ésta ascendía a entre 1.300 a 1.500 hombres en más de una veintena de compañías. Aunque las cifras de aportaciones eran notables, tanto de infantería como de caballería, siempre estaban bastante por debajo de los ofrecimientos formales del reino para su propia defensa. Pero siempre que había alguna necesidad, o para participar en las campañas estivales, las milicias de todo el reino podían ser movilizadas. Durante noviembre de 1665, tras la importante entrada del ejército portugués del Conde do Prado en Galicia, que consiguió tomar A Guarda y saquear Bouzas y Porriño ${ }^{40}$, las milicias del reino fueron llamadas en masa para defender la frontera. En la frontera de Tuy, que abarcaba también otros puntos clave como Monzón y Salvatierra, se llegaron a concentrar más de 10.000 milicianos, algunos provenientes de lugares tan alejados como Malpica o Ribadeo. Junto a estas tropas se concentraban otros 5.400 infantes de los tercios pilones y 2.300 hombres de la caballería, de los que más de 1.300 eran oriundos del reino. A todas estas cifras habría que sumar los aproximadamente 700 hombres de los tercios pilones que quedaron prisioneros tras la rendición de A Guarda y otros tantos que quedaron para la defensa de Monterrey y Verín. Con todo, las cifras indican que el propio reino podía movilizar en caso de necesidad más de 17.000 hombres, aunque esto no significaba

39 Carta de don Vicente Gonzaga, Gobernador del Reino de Galicia, Pontevedra 21 de diciembre 1657. A.G.S. G.A. Leg. 1.911. Resumen de lo resuelto sobre la formación de los diez tercios de Milicias de Galicia, 1667. A.G.S. G.A. Leg. 2.159.

40 EIRAS ROEL, Antonio: "Las Juntas del Reino de Galicia y la fase final de la Guerra de Portugal" en Actas de las Juntas del Reino de Galicia. Tomo VIII: 1666-1677, Santiago de Compostela, 2001, pp. 18-25. 
que las tropas fueran de confianza y que estuvieran interesadas en luchar, como bien indica el hecho que pese a la magnitud de fuerzas en esa campaña no se volviera a intentar recuperar A Guarda ${ }^{41}$.

Desde 1648 a menudo el reclutamiento de los tercios pilones, ante la falta de voluntarios, había sido aprovechado sucesivamente para reclutar hombres para Flandes y la Armada, contraviniendo claramente los servicios concedidos por el reino para la defensa de la frontera. Así en 1648 y 1649, tanto en Conde de Altamira como Juan Pardo de Figueroa, Gobernador de La Coruña, se encargaron de realizar distintos reclutamientos que supusieron en envío a Flandes de parte de los soldados pilones reclutados en el reino, ya fueran estos de su voluntad o forzados, además de la aplicación de condenados y voluntarios reclutados mediante la intervención de sus propios capitanes ${ }^{42}$. Pero estas acciones pronto tuvieron la respuesta del propio reino, que intentó por todos los medios que estas acciones reclutadoras terminasen para que todos los esfuerzos se concentraran en la defensa del reino ${ }^{43}$, algo que más o menos se cumplió, ya que a partir de 1653 no veremos más levas en Galicia para Flandes en un periodo de más de 14 años.

Pero el final de la guerra con Portugal hará que las cosas cambien. En 1668 ya no sólo se enviará a Flandes un puñado de reclutas de los tercios pilones, sino que se enviaron tres de los tercios por completo y otras 28 compañías de los seis restantes, además de las cinco compañías fijas de las antiguas guarniciones de Monzón, Castro Laboreiro y del fuerte de San Luis Gonzaga, que ya no eran necesarias al ser demolidas por estar en el interior de Portugal. Según las certificaciones oficiales, en total llegaron a embarcarse 66 compañías con sus oficiales y 3.688 soldados y tambores, por lo que como mínimo fueron enviados a Flandes 4.000 infantes. Además igualmente se embarcaron para Flandes 27 compañías de la denominada caballería de Galicia, compuesta enteramente por naturales del reino, con aproximadamente 652 plazas de oficiales y soldados desmontados ${ }^{44}$.

41 Relación de la infantería, caballería y milicias que se halla de guarnición en las plazas de esta frontera de Tuy, 15 de noviembre 1665. Relación de los oficiales vivos, reformados y soldados y desmontados con que se halla la caballería de Galicia y Flandes, 6 de diciembre 1665. A.G.S. G.A. Leg. 2.086.

42 Carta del Conde de Santiesteban, Gobernador de Galicia, 15 de febrero 1648. A.G.S. G.A. Leg. 1.702. Junta de Guerra de España, 16 de abril y 14 de julio 1648. A.G.S. G.A. Leg. 1.682. Carta de Juan de Iriarte, Pontevedra 18 de junio 1648. A.G.S. G.A. Leg. 1.703. Carta del Arzobispo de Santiago, 12 de abril 1648. Carta del Conde de Santiesteban, Gobernador de Galicia, 11 de abril 1648. A.G.S. G.A. Leg. 1.709. Carta de don Juan Pardo de Figueroa, La Coruña 9 de octubre 1649. A.G.S. G.A. Leg. 1.741.

43 Presentación al reino de distintos Memoriales, Orense 5 de enero 1649. Documento 3-A. Actas de las Juntas del Reino de Galicia. Tomo VI: 1648-1654, Santiago de Compostela, 1999, pp. 81-82.

44 Consejo de Guerra, 24 de mayo 1669, con la carta inclusa: Relación del dinero remitido y aplicado a las levas que se levantó en el reino de Galicia, Pontevedra, 12 de abril 1669. A.G.S. G.A. Leg. 2.194 . 
Aunque estas aportaciones militares se habían concedido por el reino para el sostenimiento de la guerra con Portugal y su propia defensa, tras el estallido de la Guerra de Devolución (1667-1668) la monarquía necesitaba reforzar el ejército de Flandes - casi desmantelado tras largos años de paz en los Países Bajos- por lo que usó al reino de Galicia como gran centro reclutador. A pesar de que durante el invierno de 1667-68 en Galicia se reclutaron 1.100 hombres para Flandes entre voluntarios, forzados y las aportaciones del clero, esa cantidad era demasiado escasa, por lo que se necesitaban más hombres. La oportunidad para obtener más hombres llegó con las negociaciones de paz con Portugal, lo que permitía definitivamente desmantelar el ejército gallego, que por orden de la Reina Gobernadora pasaría en su mayor parte a Flandes, siendo el encargado de esa empresa el Condestable de Castilla. Los hombres se embarcarían desde el reino y acompañarían a don Juan de Austria, que había sido nombrado nuevo gobernador de los Países Bajos. Pero don Juan, aunque aceptó el puesto y se trasladó a La Coruña participando en los preparativos, nunca terminó embarcándose para Flandes, siendo sustituido por el Condestable, verdadero artífice del éxito de la notable movilización gallega de ese año ${ }^{45}$.

Los métodos utilizados por el Condestable de Castilla para conseguir la aplicación del ejército de Galicia a Flandes fueron sin duda curiosos. La primera decisión del gobierno de Madrid fue el envío de toda la caballería española que asistía en el reino de Galicia, manteniéndose en la península la caballería veterana llegada de Flandes en 1662. Pero la medida suscitó una enorme reticencia en los soldados y oficiales implicados, que aunque eran la parte del ejército más profesional no estaban dispuestos a abandonar su cómodo servicio cerca de sus casas, por lo que muchos abandonaron sus puestos, ya fuera por deserción como por licencia. De hecho, tras darse la orden, más de 1.000 hombres faltaron de las 27 compañías de caballería que había en el reino. Se intentó que muchos volvieran a sus puestos, al permitir a los casados quedarse en el reino e imponer fuertes penas a los fugitivos, pero estas medidas poco cambiaron la situación ${ }^{46}$.

45 Carta del Consejo de Guerra al Condestable de Castilla, Capitán General de Galicia, 28 de febrero 1668. A.G.S. Libro Reg. del Consejo de Guerra 307 f. 136. Carta de don Diego de la Torre, 24 de febrero 1668. A.G.S. G.A. Leg. 2.161.

46 Carta del Consejo de Guerra al Condestable de Castilla, Capitán General de Galicia, 13 de agosto 1668. A.G.S. Libro Reg. del Consejo de Guerra 304 f. 22. Consejo de Guerra, 11 de julio 1668. Relación de los oficiales reformados y soldados de las compañías de caballos corazas españolas del ejército de Galicia..., 12 de junio 1668. Relación de los oficiales, vivos y reformados de las tropas del trozo de Galicia que servían en el ejército que no han pasado a Flandes, 15 de junio 1668. A.G.S. G.A. Leg. 2.164. Consejo de Guerra, 24 de mayo 1669, con la carta inclusa: Relación del dinero remitido y aplicado a las levas que se levantó en el reino de Galicia, Pontevedra, 12 de abril 1669. A.G.S. G.A. Leg. 2.194. 
El problema con la caballería había sido que se la informó de su destino anticipadamente, lo que motivo importantes fugas. La infantería del ejército estaba formada por los tercios pilones, en los que servían algunos soldados voluntarios, pero la mayoría de sus componentes eran hombres que habían sido sorteados por las autoridades locales para formar parte del ejército que defendía la frontera, por lo que su reemplazo se debía efectuar anualmente debido a las deserciones y a la continua falta de soldados ${ }^{47}$. A pesar de la condición de forzados que tenían estas unidades, desde la Corona se alegó que estos eran hombres pagados por la Real Hacienda, por lo que esta podía disponer de ellos para enviarlos a donde fuera menester. La ejecución de estas órdenes era complicada, pero el Condestable de Castilla, con mucho acierto y mano izquierda, se las arregló para conseguir que buena parte de estos hombres se enviaran a Flandes. Si el exceso de información había provocado fugas entre la caballería, a la infantería no se la comunicó su destino final. Así se convocó a los tercios pilones en la frontera con Portugal con el pretexto de que se estaba ajustando la paz. En abril la flota francesa intentó destruir la pequeña escuadra de nueve navíos que había conducido desde Cádiz hasta Vigo el Marqués de Villafiel para hacerse cargo del transporte a Flandes de Don Juan y de todos los hombres posibles. Con motivo de esta acción varios de los tercios pilones fueron convocados para defender Bayona y Vigo ante un posible desembarco, pero tras la retirada de la flota enemiga se embarcaron para Flandes cerca de 4.000 componentes de estos tercios. Se intentó que la mayor parte por hombres fueran jóvenes solteros sin ninguna carga familiar, pero no siempre se consiguió, cometiéndose distintas injusticias. Con la llegada de esta expedición se transplantaron a Flandes dos tercios compuestos exclusivamente por gallegos, los de don Fernando Valladares y don Pedro Aldao ${ }^{48}$.

\section{d) Los servicios del reino}

Tras la salida masiva de los tercios pilones en 1668, la Corona volvió a intentar en años posteriores que Galicia repitiera su aportación, alegando que el servicio concedido era indefinido y que en ningún caso todos los soldados pilones habían salido

47 Resumen de lo resuelto sobre la formación de los diez tercios de Milicias de Galicia, 1667. A.G.S. G.A. Leg. 2.159. También ha tratado el tema EIRAS ROEL, Antonio: "Las Juntas del Reino de Galicia y la fase final de la Guerra de Portugal" en Actas de las Juntas del Reino de Galicia. Tomo VIII: 1666-1677, Santiago de Compostela, 2001, pp. 4-34.

48 Carta del Condestable de Castilla, Gobernador del Reino de Galicia, 11 de marzo 1668. A.G.S. G.A. Leg. 2.162. Consejo de Guerra, 24 de mayo 1669, con la carta inclusa: Relación del dinero remitido y aplicado a las levas que se levantó en el reino de Galicia, Pontevedra, 12 de abril 1669. A.G.S. G.A. Leg. 2.194. Carta del Marqués de Villafiel, Vigo 17 de abril 1668. A.G.S. G.A. Leg. 3.506. Consejo de Estado, 26 de julio 1668. A.G.S. Estado Leg. 2.687. 
del reino. Pero en ninguna ocasión el reino cedió a las pretensiones de la Corona, siempre algo elevadas ${ }^{49}$. Finalmente en 1671 se moderó la petición de la Corona que ya solamente exigía 1.000 hombres en compañías sueltas para remplazar las dotaciones de los tercios gallegos que había en Flandes, para lo que el reino podría realizar una leva forzosa de todos los fugitivos del ejército que se encontraran allí. Pero el método no resultaba, ya que como se decía “...son pocos los soldados fugitivos que ay en el, porque estos ordinariamente buscan tierra mas desaogada", por lo que estos emigraban a otras partes, sobre todo a Castilla y Andalucía para trabajar ${ }^{50}$. Al final, para evitar las molestias y cumplir con los mandatos del rey, el reino de Galicia se comprometió a realizar un servicio de 1.000 hombres para Flandes, además de ofrecer un donativo económico a la Corona de 40.000 escudos. El reclutamiento de los hombres se efectuó como venía haciéndose habitualmente para los tercios pilones, repartiendo el número pedido entre las parroquias de las siete provincias según la población de cada una de ellas. De esta manera, aproximadamente 1.100 hombres salieron para Flandes gracias a este servicio ${ }^{51}$.

Aunque el rey en cualquier momento podía decretar en Galicia una recluta forzosa, sin necesidad siquiera de la aprobación de las provincias, lo cierto es que sin la colaboración del reino cualquier leva era difícil de llevar a cabo. Esta colaboración podía ser de diferentes maneras, ya fuera a través de la concesión de un servicio a la Corona en hombres, o a través de la ayuda ofrecida para poder quintar a la población. En los servicios los representantes del reino ofrecían servir al rey con cierto número de hombres, muchas veces a cambio de algo, como el encabezamiento de las rentas reales del reino pedido en 1674 o el tanteo sobre diversas rentas reales conseguido en 1677. De igual modo era necesaria la colaboración del reino para que gracias a sus ministros se pudiera lograr quintar equitativamente a la población para conseguir alguna leva. Para esto era importante la Junta del reino de Galicia, pero no siempre era esencial, ya que en ocasiones el reino aportó hombres sin necesidad que la junta se reuniera, como ocurrió en 1672 o 1684, negociando la Corona directamente con las diversas provincias.

49 Carta de don Diego Sarmiento, 5 y 25 de septiembre 1671. Consejo de Estado, 26 de agosto 1671. A.G.S. G.A. Leg. 2.220 .

50 Carta del veedor general de Galicia, 4 de diciembre 1671. Consejo de Guerra, 7 de diciembre 1671. A.G.S. G.A. Leg. 2.220 y 2.247.

51 Carta del Consejo de Guerra al Arzobispo de Santiago, Gobernador en interinidad del Reino de Galicia, 15 de enero 1672. A.G.S. Libro Reg. del Consejo de Guerra 316 f. 78. Carta del Arzobispo de Santiago en la que se incluyen las relaciones del gasto que de la leva a Flandes, 4 de septiembre 1672. Informe del veedor del reino de Galicia, 22 de noviembre 1681. A.G.S. G.A. Leg. 2.284 y 2.581. Voto del regidor-procurador de Santiago sobre la prórroga del servicio de millones y otros solicitada por el monarca. Vigo 20 de julio 1679. Documento 116-D. Actas de las Juntas del Reino de Galicia. Tomo IX: 1677-1679, Santiago de Compostela, 2001. 
En las juntas del reino celebradas en el mes de octubre de 1673 los distintos representantes del reino y las provincias tomaron cuenta de las aparentes ventajas que tendría la concesión al propio reino de los encabezamientos de las rentas cobradas en Galicia. A cambio de la concesión se ofrecía al rey un donativo económico de 80.000 escudos y servicio de 1.000 hombres en un tercio para Flandes. Gracias a esto los habitantes del reino no sólo evitarían las extorsiones ejecutadas por los arrendatarios de esas rentas, sino que incluso se evitaría la presión económica, ya que con el cobro directo de estos impuestos habría dinero suficiente para poder pagar el donativo económico ofrecido e incluso sobraría ${ }^{52}$. Este método en el que el reino ofrecía servir con hombres y dinero a cambio de una concesión real no va a ser una novedad, por lo que en 1676 nuevamente el reino sirvió con un tercio de 1.000 hombres y el pago de un donativo económico de 100.000 escudos a cambio de conceder los tanteos sobre diversos impuestos reales cobrados por la Corona en el reino ${ }^{53}$.

Pero el reino de Galicia, y especialmente sus representantes, a raíz de estos servicios también se beneficiaban de otras concesiones reales. Por un lado el rey premiaba a la clase dirigente más afecta a los intereses de la Corona a través de la concesión de premios económicos, ayudas de costa y especialmente hábitos de las órdenes militares o un ascenso en el escalafón de la administración gubernamental. Para la obtención de estos premios los diputados de las provincias debían liderar o ayudar a que las peticiones de servicios propuestas al reino tuvieran éxito, ya fuera dentro o fuera de las propias juntas del reino. Esto suponía un verdadero juego encubierto de intereses, en el que los sujetos que imponían los intereses de la monarquía a los de la provincia o ciudad a la que representaban salían beneficiados personalmente, no sólo gracias a estos premios, sino que incluso aumentaban su poder imponiéndose sobre el resto de la sociedad.

Otro importante premio para la oligarquía del reino eran las patentes en blanco que el Consejo de Guerra entregaba para todos los oficiales de los tercios y compañías formadas en el reino mediante la realización de un servicio. La existencia de estas patentes en blanco suponía que el nombramiento efectivo de los oficiales recaía

52 Junta del Reino de Galicia, 22 de octubre 1673. Documento 57-D. Actas de las Juntas del Reino de Galicia. Tomo VIII: 1666-1677, Santiago de Compostela, 2001.

53 Carta del Conde de Aranda, Capitán general del reino de Galicia, 1 de marzo 1676. Consejo de Guerra, 16 de noviembre 1676. Carta del reino de Galicia a la reina gobernadora, 11 de noviembre 1676. Carta de la provincia de Mondoñedo, 4 de agosto 1676. A.G.S. G.A. Leg. 2.347, 2.374 y 2.371. Copia del pliego dado por don Álvaro de Losada Ribadeneira solicitando al Consejo de Hacienda en Sala de Millones la concesión al Reino de Galicia del tanteo de las sisas de los servicios de 24 millones y ocho mil soldados en las mismas condiciones en que las llevaba arrendadas don Diego Caballero, Madrid 6 de abril 1675. Documento 14-D. Actas de las Juntas del Reino de Galicia. Tomo VIII: 1666-1677, Santiago de Compostela, 2001. 
en los propios representantes de las provincias, que repartían los cargos oficiales entre sus allegados o sus hijos. Además estas patentes solían ir unidas a los suplimentos, documentos oficiales que permitía a cualquiera ser oficial del ejército sin necesidad de atestiguar servicios militares anteriores, no vulnerando así las ordenanzas militares. Esto suponía que muchos hijos segundones de la oligarquía local vean una buena oportunidad de convertirse en oficiales del ejército sin necesidad siquiera de tener experiencia, desempeñando un cargo que a la larga les podrá reportar otros beneficios honoríficos o catapultarles hacia un mayor ascenso social.

En ocasiones la existencia de estas patentes en blanco ayudarán a que el reino se comprometa a reclutar los hombres pedidos por la Corona. En 1689 se veía problemático el envío a Flandes de una importante recluta de 3.000 hombres. Pero con la formación de tres tercios, de los que el reino podría nombrar todos los oficiales, el servicio se mostró mucho más posible. De hecho, incluso antes de que el reino confirmara el servicio, en el seno de la Junta General del reino los representantes de las provincias comenzaron a nombrar a los principales cargos de la recluta ante su notable interés por hacerse con una parte del premio que constituían las patentes ${ }^{54}$.

Ante la falta de voluntarios los servicios realizados por el reino se ejecutaban repartiendo el número de hombres indicado entre las feligresías del reino atendiendo a su vecindad. Pero como indicaba el Consejo de Guerra esta medida necesitaba de la aprobación y colaboración de las ciudades para que la leva llegara a buen fin y se realizase rápidamente. Pero esta cooperación no era gratuita. No sólo la Corona debía entregar las patentes en blanco para los oficiales, sino que también se debía permitir que los mediadores locales realizaran diversas injusticias. En la mayoría de los casos estas consistían en reservar a algunas personas de la leva, obligando a los más pobres a aportar la mayoría de las contribuciones, tanto económicas como humanas. Así informaba de ello el Consejo de Guerra: “...aquellos caballeros y regidores de las ciudades se interesan en reservar a unos y embiar a otros por la fuerza, vengando sus pasiones y usando de sus afectos" ${ }_{55}$.

54 Consejo de Estado, 27 de marzo 1691. Carta del Conde de Puñoenrostro, Gobernador del reino de Galicia, 12 de diciembre 1691. A.G.S. Estado Leg. 4.171. Junta del reino de Galicia, 31 de marzo y 1 de abril 1689. Documentos 52-A y 53-A. Real cédula convocatoria de Junta de Reino para tratar de la leva de tres mil hombres para Flandes solicitados a Galicia. Buen Retiro 28 de febrero 1689. Documento 9-B. Propuestas del Reino al Gobernador-Capitán General en razón de la leva de tres mil soldados para Flandes que se está llevando a cabo. La Coruña 2 de abril 1689. Documento 282-D. Actas de las Juntas del Reino de Galicia. Tomo X: 1679-1689, Santiago de Compostela, 2002. También ha tratado el tema EIRAS ROEL, Antonio: "Las Juntas del Reino de Galicia en la década de 1680" en Actas de las Juntas del Reino de Galicia. Tomo X: 1679-1689, Santiago de Compostela, 2002, pp. 25-28.

55 Consejo de Guerra, 9 de octubre 1693. Junta de Tenientes Generales, 15 de noviembre 1693. A.G.S. G.A. Leg. 2.914 y 2.916. 
La realización de los servicios implicaba el reparto proporcional de la cantidad de hombres acordada por el reino entre las siete provincias, muy diferentes entre si en territorio y población ${ }^{56}$. Las mismas provincias, representadas por sus ciudades, eran las que generalmente se debían encargar de cumplir con el cupo pedido, repartiéndolo en todos los lugares de su jurisdicción según su población. Pero aunque se estableciesen cupos, muchos servicios también implicaban que una determinada provincia se comprometía a aportar más hombres a la Corona. Esto suponía un notable incremento dentro del número de hombres repartido, suponiendo en ocasiones incluso el grueso de las aportaciones. Los servicios se formalizaban a través de la negociación entre la provincia y el gobernador del reino, en ella las provincias se solían comprometer a aportar más hombres a cambio muchas veces de más patentes para formar compañías. De esta manera muchas provincias redondeaban al alza el número de hombres que se las había repartido para poder formar compañías independientes y no tener que negociar el nombramiento de los oficiales con el resto, lo que en la práctica suponía un beneficio para la $\mathrm{Corona}^{57}$.

Tabla IV: Repartimiento provincial de los diferentes servicios del reino de Galicia para Flandes:

\begin{tabular}{|l|c|c|c|}
\hline Provincias & $\begin{array}{c}\text { 1678, repartimiento teóri- } \\
\text { co (no se llegó a producir) }\end{array}$ & 1672, soldados aportados & $\begin{array}{c}\text { 1674, soldados ofrecidos } \\
\text { por las diferentes pro- } \\
\text { vincias }\end{array}$ \\
\hline Betanzos & 91 & 92 & 100 \\
\hline Santiago & 334 & 352 & 400 \\
\hline Coruña & 63 & 90 & 80 \\
\hline Lugo & 167 & 170 & 90 \\
\hline Orense & 167 & 171 & 200 \\
\hline Tuy & 91 & 96 & 90 \\
\hline Mondoñedo & 91 & 91 & 110 \\
\hline Total: & 1.004 & 1.062 & 1.070 \\
\hline
\end{tabular}

Fuente: Actas de las Juntas del Reino de Galicia. Tomo IX: 1677-1679, Santiago de Compostela, 2001. A.G.S. G.A. Leg. $2.242,2.284$ y 2.301 .

\section{e) Las cifras totales}

No es fácil en tan poco espacio hacer un balance total del reclutamiento realizado en Galicia durante la segunda mitad del siglo XVII, por lo que por ello debemos

56 RUÍZ ALMANSA, Javier: La Población de Galicia (1500-1945), Tomo I, Madrid, 1948, pp. 219-223.

57 Carta de la provincia de Mondoñedo, 4 de agosto 1676. Carta del Conde de Aranda, Gobernador del reino de Galicia, 2 de agosto 1676. Carta del licenciado don Joseph Sánchez, La Coruña, 25 de julio 1676. A.G.S. G.A. Leg. 2.371. Carta del Conde de Aranda, Gobernador del reino de Galicia, 19 de julio 1676. A.G.S. G.A. Leg. 2.374. 
recurrir a un cuadro resumen en el que se incluyen las aportaciones de hombres que desde Galicia se llegaron a transportar a Flandes. Estas cifras no suponen el reclutamiento total realizado en el reino durante todo este largo periodo, sino que son los hombres que efectivamente se reclutaron y enviaron a Flandes según los datos de embarque y no según las órdenes de reclutamiento u otras estimaciones. Tampoco tienen cabida en este cuadro las aportaciones del reino de Galicia a la defensa de su propia frontera con Portugal o las aportaciones a la Armada u otros frentes de la monarquía, aunque estas últimas son más bien escasas. Pese a esta acotación de destino, las cifras hablan por si solas, informándonos de una verdadera diáspora gallega a Flandes, especialmente acentuada desde 1668 a 1689.

\section{El viaje a Flandes: Una difícil travesía}

La vía de llegada a Flandes más común de los soldados españoles durante el siglo XVI había sido el denominado "Camino Español", corredor militar terrestre que cruzaba media Europa a lo largo de aproximadamente 1.000 kilómetros, desde Génova -donde desembarcaban los españoles de su viaje por mar desde las costas mediterráneas- hasta Namur. Esta ruta permitía las comunicaciones y el envió de tropas por tierra desde Italia hasta los Países Bajos, siendo una de las piezas claves del sistema español ${ }^{58}$. Su cierre tras la toma de la plaza de Breisach, en 1638, supondrá su definitivo cierre, pero esto no significará que los españoles dejen de seguir llegando a los Países Bajos. Desde comienzos del siglo XVII, a pesar del fracaso de la Armada Invencible, se comenzó a enviar refuerzos por mar desde la península con mucha mayor asiduidad, gracias a la nueva política naval. Ante el cada vez más complicado viaje a Flandes por tierra, la monarquía encontró a lo largo de las décadas de 1620-30 la solución, gracias a nuevas expediciones marítimas hacia el Mar del Norte protagonizadas en gran medida por las fragatas de la Armada de Flandes y sus expertos marinos, que exitosamente realizaron sus funciones de corso y transporte de tropas entre la península y los puertos flamencos ${ }^{59}$.

Pero la gran expedición naval de Oquendo de 1639, enviada por la monarquía para intentar no sólo transportar tropas a Flandes, sino también para destruir la Armada holandesa, fue un enorme fracaso que dejó maltrecha la flota hispana, aunque una buena parte de los hombres que transportaba pudieron desembarcarse antes de

58 PARKER, Geoffrey: La Gran Estrategia de Felipe II, Madrid, 1998, pp. 214-215. PARKER, Geoffrey: El ejército de Flandes y el Camino Español 1567-1659, Madrid, 1991.

59 STRADLING, Robert A.: La Armada de Flandes. Política naval española y guerra europea 1568-1668, edición española, Madrid, 1992. 
De Galicia a Flandes: reclutamiento y servicio de soldados gallegos en el ejército de Flandes (1648-1700)

Tabla V: Cifras totales de reclutamiento en Galicia para Flandes desde 1648-1700:

\begin{tabular}{|c|c|c|c|}
\hline Años & Reclutas & Plazas & Tipo de leva \\
\hline 1648 & $\begin{array}{l}\text { Reclutamiento a cargo del } \\
\text { Conde de Altamira }\end{array}$ & 500 aprox. & $\begin{array}{l}\text { Voluntarios, forzados y } \\
\text { reclutados a costa de sus } \\
\text { capitanes }\end{array}$ \\
\hline 1649 & $\begin{array}{l}\text { Leva a cargo de don Juan } \\
\text { Pardo de Figueroa }\end{array}$ & 1.000 aprox. & Forzados \\
\hline $1649-50$ & $\begin{array}{l}\text { Reclutamiento por asiento } \\
\text { realizado por don Pedro } \\
\text { de Villela }\end{array}$ & 800 aprox. & Asiento \\
\hline 1653 & $\begin{array}{l}\text { Servicio pedido a diferen- } \\
\text { tes ciudades, la iglesia y } \\
\text { nobleza }\end{array}$ & 226 & Repartimiento \\
\hline 1668 & $\begin{array}{l}8 \text { compañías de voluntarios } \\
\text { y forzados }\end{array}$ & 842 & Voluntarios-forzados \\
\hline 1668 & $\begin{array}{l}3 \text { compañías del servicio } \\
\text { del Arzobispado de Santia- } \\
\text { go y las Religiones de San } \\
\text { Benito y San Bernardo }\end{array}$ & 320 & Servicio de la iglesia \\
\hline 1668 & Tercios y soldados pilones & 4.000 & Ejército de Galicia \\
\hline 1668 & Desmontados del ejército & 650 & Ejército de Galicia \\
\hline 1672 & Recluta de 10 compañías & 1.100 & Repartimiento \\
\hline 1672 & $\begin{array}{l}\text { Tres compañías de des- } \\
\text { montados }\end{array}$ & 175 aprox. & Voluntarios \\
\hline 1674 & $\begin{array}{l}\text { Tercio del Conde de Ama- } \\
\text { rante }\end{array}$ & 1.400 & $\begin{array}{l}\text { Repartimiento-algunos } \\
\text { voluntarios }\end{array}$ \\
\hline 1675 & $\begin{array}{l}\text { Cinco compañías del Ter- } \\
\text { cio del Marqués de Arcos } \\
\text { Tenorio }\end{array}$ & 449 & Voluntarios \\
\hline 1676-77 & $\begin{array}{l}\text { Tercio de don Manuel Sar- } \\
\text { miento }\end{array}$ & 1.003 & $\begin{array}{l}\text { Repartimiento-algunos } \\
\text { voluntarios }\end{array}$ \\
\hline 1680 & $\begin{array}{l}\text { Tercio del Conde de Grajal } \\
\text { (4 compañías) }\end{array}$ & 370 aprox. & Voluntarios \\
\hline 1683 & $\begin{array}{l}\text { Recluta de dos compañías } \\
\text { por capitanes llegados de } \\
\text { Flandes }\end{array}$ & 202 & Voluntarios \\
\hline 1684 & $\begin{array}{l}\text { Tercio de don Antonio } \\
\text { Mariño }\end{array}$ & 1.983 & $\begin{array}{l}\text { Repartimiento-servicio de } \\
\text { la iglesia }\end{array}$ \\
\hline 1689 & $\begin{array}{l}\text { Tres tercios: Marqués de } \\
\text { Casasola, don Jacinto } \\
\text { Sarmiento Zamudio y don } \\
\text { Pedro de Aldao }\end{array}$ & 2.866 & Repartimiento \\
\hline \multirow[t]{2}{*}{1692} & $\begin{array}{l}\text { Siete compañías para la } \\
\text { recluta de sus tercios }\end{array}$ & 691 & $\begin{array}{l}\text { Repartimiento-servicio de } \\
\text { la iglesia }\end{array}$ \\
\hline & Total aproximado: & 18.577 & \\
\hline
\end{tabular}

Fuente: A.G.S. G.A. Leg. 1.682, 1.702, 1.703, 1.709, 1.732, 1.733, 1.741, 1.825, 2.161 у 2.194. 2.133, 2.161, 2.164, 2.165, $2.194,2.259,2.284,2.301,2.302,2.367,2.370,2.371,2.374,2.375,2.397,2.479,2.580,2.581,2.583,2.609,2.610,2.611$, 2.641, 2.793 y 2.823 y 2.905. A.G.S. Libro Reg. del Consejo de Guerra 216, 234, 316, 325 y 365. A.G.S. Estado Leg. 2.121, $3.874,3.875,3.878,3.882$ y 4.102 . B.N.Madrid Mmss. 9.888. 
la pérdida de los navíos ${ }^{60}$. El desastre contribuyó a la debilidad de la marina hispana, pero no hizo que los viajes entre España y Flandes dejaran de producirse. Pese a que continuamente se haya interpretado la derrota naval de las Dunas (1639), la pérdida de Breisach (1638) y la derrota de Rocroi (1643) como los hitos que marcarán el fin de la notable presencia española en Flandes, lo cierto es que en ningún momento los soldados españoles dejarán de llegar a los Países Bajos. Incluso en 1640, al año siguiente de la derrota de la flota de Oquendo, llegaron a Flandes tropas por mar desde la península, 1.200 sardos y 11 compañías de españoles reunidas en La Coruña ${ }^{61}$.

Pero si bien los españoles continuaron llegando por vía marítima a Flandes durante el resto del siglo XVII, lo harán de una manera muy diferente. La unión entre la península y los puertos flamencos durante las décadas de 1640-50 -a pesar de la precariedad del sistema- siguió realizándose habitualmente gracias a los navíos de la Armada de Flandes, que en pequeñas expediciones se encargaron de transportar tropas de un lado a otro ${ }^{62}$. Pero la continua debilidad de la Armada hará que progresivamente las rápidas fragatas flamencas pierdan efectivos, a la vez que estos navíos atlánticos tengan que ser empleados en las costas mediterráneas españolas e italianas. Para el caso gallego, entre 1648-1700 solamente 10 navíos de 70 barcos participantes en las expediciones navales que conocemos eran buques de la Armada, ya fuera de la del Mar Océano o la de Flandes. Esto significa que solamente en dos fechas concretas los navíos de la Armada fueron los encargados realmente del transporte a Flandes de las tropas reclutas en Galicia. En 1668 siete navíos de la Armada del Marqués de Villafiel serán los encargados de llevar a Ostende a parte de los soldados de los tercios pilones, y en 1680 otros tres buques a cargo de Miguel de Oquendo transportarán los soldados reclutados para el tercio del Conde de Grajal y al nuevo gobernador de los Países Bajos ${ }^{63}$.

La primera experiencia de transporte privado de hombres a Flandes a través de navíos mercantes extranjeros se realizó en 1639, mediante la expedición de B. Wrigth, en la que varios navíos de pabellón ingles transportaron unos 1.500 españoles desde Málaga y Cádiz hasta Dunquerque. Pero la experiencia no salió tan bien como se esperaba, ya que varios de los barcos fueron apresados por los holandeses sin opo-

60 ALCALÁ-ZAMORA Y QUEIPO DE LLANO, José: España, Flandes y el Mar del Norte (1618-1639). La última ofensiva europea de los Austrias madrileños, Barcelona, 1975.

61 Sucesos de Flandes de 1637, 1639 y 1640 narrados por el alférez don Lorenzo Cevallos y Arce, en Colección de libros españoles raros o curiosos, Tomo XIV, Madrid, 1880, pp. 263-264.

62 STRADLING, Robert A.: La Armada de Flandes. Política naval española y guerra europea 1568-1668, Madrid, 1992, pp. 165-169. PARKER, Geoffrey: El ejército de Flandes y el Camino Español 1567-1659, Madrid, 1991, p. 118.

63 Carta del Marqués de Villafiel, Gobernador del reino de Galicia, 22 de septiembre 1680. Consejo de Guerra, 7 de octubre 1680. A.G.S. G.A. Leg. 2.479. Orden real del 21 de agosto 1680. Informe del veedor del reino de Galicia, 22 de noviembre 1681. A.G.S. G.A. Leg. 2.497 y 2.581. Carta del secretario don Crispín Botello, Bruselas 4 de diciembre 1680. A.G.S. Estado Leg. 4.102. 
ner estos casi resistencia ${ }^{64}$. Pese a esta circunstancia negativa la Monarquía española debió contar habitualmente con contratistas privados para transportar hombres a Flandes, ya fueran españoles o extranjeros. En 1649 sabemos que el buque que llevó 400 hombres desde La Coruña a Flandes era un navío mercante inglés que se llamaba el Globo de Londres, ya que no se encontró a ningún patrón de navío vecino de La Coruña que quisiera hacerse cargo del flete ${ }^{65}$. Pero pese a la continua presencia de mercantes extranjeros, cuando se podía el transporte se realizaba a través de navíos de corso, mejor preparados y habilitados para el transporte de tropas que los simples mercantes, además de ser buques habituales de las costas españolas, especialmente hasta $1668^{66}$. Aunque en ocasiones los navíos corsarios podían ser gallegos, lo cierto es que estos eran una minoría, ya que en muchos casos el transporte estará monopolizado por barcos originarios de puertos flamencos, especialmente de Ostende, tras la definitiva pérdida de Dunquerque en 1658.

La Paz de Westfalia (1648), y el posterior acercamiento entre España y Holanda ${ }^{67}$, pondrán las cosas mucho más fáciles para el envío a Flandes de hombres, al consolidarse las Provincias Unidas como el mejor aliado de España, por lo que la Corona española no tendrá que depender de los continuos virajes de la política británica. A partir de esa época el trasporte marítimo será mucho más viable al poder encontrar protección de cualquier flota enemiga en los puertos holandeses, además de la posibilidad de que el transporte se pueda realizar en navíos mercantes de su pabellón. Así, especialmente a partir de la Guerra de Holanda (1672-1678), el transporte de tropas a Flandes desde Galicia quedará en manos de Adrián de Roo, un conocido empresario holandés asentado en La Coruña ${ }^{68}$, que en numerosas ocasiones se encargará de concertar el flete de las embarcaciones necesarias para el transporte de

64 PARKER, Geoffrey: El ejército de Flandes y el Camino Español 1567-1659, Madrid, 1991, p. 117. Sucesos de Flandes de 1637, 1639 y 1640 narrados por el alférez don Lorenzo Cevallos y Arce, en Colección de libros españoles raros o curiosos, Tomo XIV, Madrid, 1880, p. 245.

65 Relación de la infantería de levas que se embarcó en este presidio de la ciudad de La Coruña para los estados de Flandes en 22 de febrero, La Coruña 7 de marzo 1649. Carta de don Juan Pardo de Figueroa, Gobernador de las Armas de La Coruña, 7 de febrero 1649.A.G.S. G.A. Leg. 1.732.

66 OTERO LANA, Enrique: Los corsarios españoles durante la decadencia de los Austrias. El corso español en el Atlántico peninsular en el siglo XVII (1621-1697), Madrid, 1992, p. 49 y ss.

67 HERRERO SÁNCHEZ, Manuel: El Acercamiento hispano-neerlandés (1648-1678), Madrid, 2000.

68 Junto con su socio Baltasar Kiel será el responsable de importantes asientos para el abastecimiento de lona y jarcias para la Armada, además de montar en Sada una industria textil. SÁNZ AYÁN, Carmen: "Negociadores y capitales holandeses en los sistemas de abastecimientos de pertrechos navales de la Monarquía Hispánica durante el siglo XVII” en Hispania No 182, Madrid, 1992, pp. 941 y 945. Debemos afirmar que estos contratos de transporte privados eran sin duda muy lucrativos para Adrián de Roo, que podía aprovechar la llegada de los barcos que dejaban en Galicia pertrechos navales de Holanda para devolverlos a los Países Bajos con soldados, aprovechando el flete de vuelta, no teniendo que volver los barcos de vacío. 
los soldados gallegos a Flandes, casi siempre a un precio bastante razonable, siendo mucho más barato este método que la utilización de los cada vez más escasos navíos de la Armada ${ }^{69}$.

Pero incluso este sistema privado de transporte llegará a convertirse en un método mucho más elaborado durante la Guerra de los Nueve Años. En agosto de 1689 los 2.866 oficiales y soldados reclutados en Galicia se enviarán a Flandes en un convoy de mercantes holandeses, formado por cinco navíos mercantes, dos barcos menores que se encargaron de transportar armas de fuego para las tropas y al menos un galeón de guerra que protegía todo el convoy. La pequeña flota de transporte holandesa había sido fletada por asiento, gracias a la estrecha colaboración surgida entre Madrid y Ámsterdam durante la guerra en la que ambas naciones eran aliadas. Este sistema suponía el transporte privado de tropas españolas por navíos mercantes de sus aliados, que además estaban bien armados y acompañados de buques de guerra que ofrecían una gran protección ante la posibilidad de un asalto corsario o de un ataque de la flota francesa ${ }^{70}$.

De hecho siempre estaba presente el peligro de que las tropas transportadas por mar pudieran caer en manos enemigas al ser capturados los barcos, aunque también era constante la posibilidad de algún naufragio. De los 70 navíos que conocemos que realizaron labores de transporte de tropas entre Galicia y Flandes, solamente dos fueron capturados por los franceses, no naufragando ninguno. La fragata particular San Carlos de Ostende, con 300 hombres abordo, encalló en diciembre de 1676 en las complicadas costas flamencas, lo que permitió que la flota francesa de Dunquerque capturará el navío. Durante años los franceses se negaron a devolver a los soldados capturados, pese a la insistencia de los ministros españoles de Bruselas, lo que supuso un duro calvario para los hombres ${ }^{71}$. En junio de 1684 tres mercantes holandeses transportaron a Flandes a parte del tercio de don Antonio Mariño, pero uno de los barcos, un pingüe holandés con cerca de 200 hombres, fue apresado por dos fragatas francesas en las cercanías de Dunquerque. Pero los distintos intentos realizados por el Marqués de Grana para liberar a los soldados, antes y después de firmar la tregua con Francia, no dieron los resultados esperados, por lo que los franceses tardaron

69 Consejo de Guerra, 12 de octubre 1676. A.G.S. G.A. Leg. 2.347. Consejo de Guerra, 7 de octubre 1679. A.G.S. G.A. Leg. 2.440. Consejo de Guerra, 21 de enero 1680. A.G.S. G.A. Leg. 2.476.

70 Relación de los oficiales y soldados y el número de todos que van embarcados desde este puerto de La Coruña a Ostende, 14 de agosto 1689. Relación de los transportes holandeses que han llegado a la Coruña, 15 de julio 1689. A.G.S. G.A. Leg. 2.793 y 2.823.

71 Carta de don Diego Gómez de Espinosa para don Pedro de Oreytia, Ostende, 27 de diciembre 1676. Carta de don Diego Decio para don Pedro de Oreytia, Ostende, 28 de diciembre 1676. Carta del Duque de Villahermosa, Bruselas, 6 de enero 1677. A.G.S. G.A. Leg. 2.397. Consejo de Estado, 23 de marzo 1677. A.G.S. Estado Leg. 2.133. 
bastante tiempo en restituir los hombres apresados. La política empleada por los franceses era clara, intentar dificultar la llegada de los españoles a Flandes ${ }^{72}$.

Uno de los factores primordiales que hacía que el lugar de servicio habitual de los soldados gallegos fuera Flandes, era la facilidad del transporte por mar de estas tropas, ante las nuevas bases marítimas aparecidas en Galicia desde finales del siglo XVI. Pero también influían en este hecho las corrientes oceánicas y los vientos, que facilitaban notablemente las comunicaciones entre las costas gallegas y el Mar del Norte, haciendo incluso más fácil la travesía que desde otras latitudes. A pesar de la mayor cercanía a Flandes de los puertos vascos - que incluso tenían más costumbre en realizar viajes a los Países Bajos, debido al tradicional transporte de la lana castellana $^{73}$-, desde Galicia solía ser más barato y seguro el viaje marítimo hasta el mar del norte ${ }^{74}$. Las corrientes y los vientos favorables hacían que los barcos pudieran entrar en el Canal de la Mancha en pocos días sin riesgo de acercase demasiado a las costas francesas, aunque siempre la rapidez dependía del estado de la mar.

Es difícil saber con precisión el tiempo que tardaban en llegar las expediciones navales desde Galicia a Flandes, debido a que la información a veces no es excesivamente precisa, ya que se solía pasar muestra a los hombres al ser embarcados, pero no al salir de puerto, al intentar aprovechar las mareas y los vientos favorables para ello, por lo que podemos observar diferencias de un día, más o menos, entre informaciones de una misma expedición. Pero pese a ese margen de error, lo más normal es que el trayecto hasta Flandes durase entre 12 a 15 días con tiempo favorable, aunque desconocemos la duración con mal tiempo o vientos en contra, pudiendo depender la duración del trayecto de la época del año o del puerto de embarque de los hombres.

El puerto de salida de la mayor parte de los navíos que llevaban los reclutas gallegos a Flandes era La Coruña, algo que no sorprende al ser el mejor puerto gallego para ese menester. De los 70 navíos que embarcan tropas gallegas para Flandes, 50 salen desde La Coruña. Vigo se confirmará como el segundo puerto de importancia, con 19 buques, aunque 18 de ellos realizan su viaje a Flandes en la coyuntura de

72 Carta del Consejo de Guerra al Duque de Uceda, Gobernador del reino de Galicia, 7 de junio 1684. A.G.S. Libro Reg. del Consejo de Guerra 365 f. 86v y ss. Consejo de Guerra, 3 de julio 1684. Carta del Duque de Uceda, Gobernador del reino de Galicia, Coruña, 18 de junio 1684. A.G.S. G.A. Leg. 2.611 y 2.641. Carta del Marqués de Grana, Gobernador de los Países Bajos, 28 de junio 1684. Carta del gobernador de Ostende, 22 de junio 1684. A.G.S. Estado Leg. 3.875.

73 ZABALA URIARTE, Aingeru: "Rutas y puertos en el comercio cantábrico del siglo XVII" en RIBOT GARCÍA, Luis y DE ROSA, Luigi (Coords.) Naves, puertos e itinerarios maritimos en la Época Moderna, Madrid, 2003, pp. 153 y ss.

74 Carta del Consejo de Guerra al Condestable de Castilla, Gobernador del Reino de Galicia, 13 y 24 de enero 1668. A.G.S. Libro Reg. del Consejo de Guerra 264, y libro 307 f. 121v. Consejo de Guerra, 7 de enero 1668. A.G.S. G.A. Leg. 2.161. 
Tabla VI: Tiempo utilizado para realizar el trayecto entre Galicia y Flandes:

\begin{tabular}{|l|c|c|}
\hline Fechas aproximadas- Puerto de Salida & Número de barcos & $\begin{array}{c}\text { Días en que realiza- } \\
\text { ron el trayecto }\end{array}$ \\
\hline 4 marzo-16 marzo 1668- La Coruña & 1 & 12 días \\
\hline 8 mayo-24 mayo 1668- Vigo & 7 & 16 días \\
\hline 16 mayo-31 mayo 1668- Vigo & 3 & 15 días \\
\hline 18 julio-29 julio 1668- Vigo & 4 & 11 días \\
\hline 12 diciembre-26 diciembre 1676- La Coruña & 1 & 14 días \\
\hline 10 mayo-25 mayo 1684- La Coruña & 3 & 15 días \\
\hline 14 agosto-30 agosto 1689- La Coruña & 6 & 16 días \\
\hline
\end{tabular}

Fuente: A.G.S. G.A. Leg. $2.367,2.375,2.397,2.581,2.611,2.641$ y 2.793. A.G.S. Estado Leg. 3.874, 3.875, 3882. A.G.S. G.A. Leg. Servicios Militares 47 y 61 .

1668, al igual que el único navío que salió del puerto de Marín hacia Flandes. Esto supone que el puerto de embarque de las tropas gallegas para Flandes va a ser La Coruña, salvo en momentos especiales como en 1668, año en el que desde Vigo y Marín se embarcan la mayor parte de los hombres del ejército de Galicia que serán enviados a Flandes, al ser convocados en las cercanías. Por otro lado el principal puerto de desembarque en Flandes, tras la pérdida de Dunquerque, será Ostende, que monopolizará la práctica totalidad de las llegadas, aunque en algunos casos algún navío deberá recalar en puertos holandeses por problemas técnicos. Este será el caso de la fragata Santa Ana de la Armada del Mar Océano, que en agosto de 1668 debió realizar su viaje a Flandes separada del resto de los navíos de la Armada por encontrarse sus mástiles en malas condiciones, algo que hizo que finalmente el navío tuviera que arribar al puerto holandés de Flesinga ${ }^{75}$.

La estacionalidad de los envíos a Flandes es otro factor importante dentro del transporte. Esta se basaba en tres factores: las condiciones de la mar, la finalización del reclutamiento y el estado de las contiendas internaciones de la monarquía. Siempre se intentaban buscar meses propicios para las travesías marítimas en el Atlántico, pero no siempre era posible que esto se cumpliera, ya que si se estaba en guerra con otras potencias había que intentar remitir los hombres en épocas en las que los navíos enemigos -ya fueran holandeses, franceses o ingleses- no estuvieran prevenidos. Además las tropas debían ser remitidas al frente lo antes posible, para evitar así las enfermedades y deserciones entre los hombres. Todos estos factores hacían que por diferentes causas las expediciones navales pudieran desarrollarse casi en cualquier mes del año. De hecho los 70 buques que tenemos constancia que realizaron su viaje a Flandes desde Galicia lo hicieron durante todos los meses del año menos en no-

75 Junta de Armadas, 13 y 21 de mayo y 28 de diciembre 1668. Carta del Condestable de Castilla, Gobernador de Galicia, 20 de mayo 1668. A.G.S. G.A. Leg. 3.506. 
viembre. Pero especialmente el periodo del año más corriente para realizar la travesía abarcaba de abril a agosto, aunque también era habitual realizar la travesía durante los primeros meses del año, fechas en las que los navíos enemigos nunca bloqueaban el Canal de la Mancha ${ }^{76}$. Esta existencia de barcos enemigos en el Canal hacia también que habitualmente las expediciones navales a Flandes estuvieran protagonizadas generalmente por navíos en solitario, o en parejas, ya que de esta manera no se llamaba la atención de las flotas enemigas. De hecho más de la mitad de los navíos que realizaron el trayecto de transporte entre Galicia y Flandes lo hicieron en solitario o en parejas, siendo pocos los que protagonizaron expediciones de más de cuatro buques.

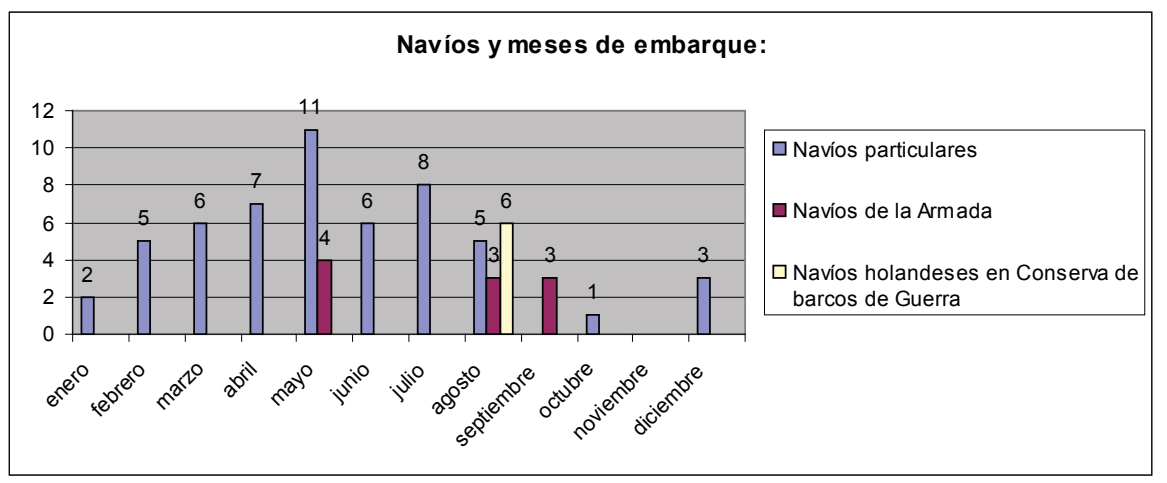

Pese a que el trayecto hasta Flandes podía ser realizado en apenas 15 días, no dejaba de ser duro para los hombres embarcados, que en ocasiones habían soportado el hacinamiento durante su espera para ser embarcados. Especialmente relevantes fueron las malas condiciones que se encontraron los reclutados durante el año 1676, ya que muchos de ellos llegaron a Flandes contagiados de peste, que contrajeron por las malas condiciones higiénicas y de habitabilidad que soportaron mientras estuvieron alojados en La Coruña ${ }^{77}$. De los cerca de 500 hombres embarcados en la Fragata Santa Teresa el 12 de diciembre de 1676, 70 murieron en el viaje. Pero el resto no se libró de las penalidades, ya que de los que llegaron a Ostende el día de navidad unos 300 estaban enfermos, por lo que iban muriendo cinco o seis cada día. Para afrontar las necesidades sanitarias de los recién llegados se creó un hospital de campaña en la ciudad para cuidar de los enfermos, proveyéndose importantes socorros económicos y alimenticios a los soldados, tanto por las autoridades del ejército como por los

76 Carta del Marqués de Castel-Rodrigo, Gobernador de los Países Bajos, 24 de febrero 1667. A.G.S. Estado Leg. 2.106.

77 Carta de don Andrés del Campo, La Coruña, 16 de junio 1680. A.G.S. G.A. Leg. 2504 
propios vecinos de la villa ${ }^{78}$. El estado era tan lamentable que con estas palabras don Diego Decio se refirió a esta gente: "no puedo sin las lágrimas en los ojos informar a Vuestra Excelencia del estado de estos pobres desdichados cristianos, muchos muertos y mas enfermos "'79.

Aunque lo ocurrido en 1676 fuera un caso sin duda grave, no constituía la norma, ya que generalmente los hombres que llegaban a Flandes solían gozar - pese al duro viaje- de una salud aceptable. En mayo de 1684 se embarcaron en La Coruña para Flandes alrededor de 1.000 hombres en tres fragatas particulares. En sólo 15 días los buques llegaron a las costas flamencas habiendo perdido a cuatro hombres en el trayecto, tanto por enfermedades como por otras circunstancias, un saldo más o menos normal en esta clase de embarques ${ }^{80}$.

\section{El servicio en el ejército de Flandes: Los soldados y las unidades gallegas}

Entre los soldados gallegos enviados a Flandes concurría la importante circunstancia de que la mayor parte de las levas realizadas en el reino eran forzosas. Pero pese a ello, lo cierto es que en general esto no significaba un sentido peyorativo de la calidad de los soldados, ya que aunque el método fuera forzoso se conseguía que los hombres fueran de calidad y que en Galicia se viera la recluta con normalidad, como si fuese voluntaria. El motivo, a ojos del Consejo de Guerra, era bien claro: "por la quietud de los naturales de aquel reyno esta diligencia de repartimiento los conduze, y puestos una vez en la profesión militar la abrazan con gusto y facilidad en pocos dias, demas de que dando las ciudades el consentimiento se tiene la leva por voluntaria"81.

Salvando la condición de forzados, lo cierto es que los soldados gallegos enviados a Flandes reunían la suficiente calidad. Durante el repartimiento se debía intentar

78 Carta de don Diego Gómez de Espinosa para don Pedro de Oreytia, Ostende, 27 de diciembre 1676. Carta del Duque de Villahermosa, Bruselas, 6 de enero 1677. A.G.S. G.A. Leg. 2.397. Relación de los oficiales y soldados que hay en los tercios de infantería española del ejército de los estados de Flandes en conformidad de la muestra y registro que se les ha pasado en diferentes días del mes de noviembre de 1676. Consejo de Estado, 23 de marzo 1677. A.G.S. Estado Leg. 2.133.

79 Carta de don Diego Decio para don Pedro de Oreytia, Ostende, 28 de diciembre 1676. A.G.S. G.A. Leg. 2.397.

80 Cartas del Consejo de Guerra al Duque de Uceda, Gobernador del reino de Galicia, 25 de abril y 7 de junio 1684. A.G.S. Libro Reg. del Consejo de Guerra 365 f. 66 y 86v. Consejo de Guerra, 12 y 25 de mayo 1684. Carta del Duque de Uceda, Gobernador del reino de Galicia, Coruña, 14 de mayo 1684. A.G.S. G.A. Leg. 2.610 y 2.641. Carta del Marqués de Grana, Gobernador de los Países Bajos, 31 de mayo y 28 de junio 1684. A.G.S. Estado Leg. 3.874 y 3.875.

81 Consejo de Guerra, 21 de enero 1680. A.G.S. G.A. Leg. 2.476. 
no causar demasiados problemas a los lugares donde se sacarían soldados, intentando que los elegidos fueran los mozos: "que se hallan con menos obligaciones, con mejor edad para servir y sin desafecto y que no inclinación a la profesión militar, para que la gente vaia mas gustosa, sea mas lúcida y se eviten las pasiones que suelen vengarse por este medio con los que tienen mano en la execución" ${ }^{2}$. Además casi siempre se intentaba que el repartimiento se realizase en invierno, para que los hombres estuvieran entregados por sus pueblos antes del mes de marzo, ya que si se tardaba más tiempo sería muy complicado conseguir a los sujetos más desocupados, por el comienzo de la emigración hacia Andalucía y Castilla con motivo de la siega.

Por lo general, se prefería que los soldados enviados a Flandes formaran parte de las familias gallegas con menos recursos. Por ello se permitía que pese a que se estableciesen quintas para sacar a los hombres, los más acomodados pudieran dar sustitutos voluntarios que tuvieran la edad y la salud apropiadas para entrar en el ejército. Con ello se intentaba que a Flandes "viniesen los más pobres y desacomodados, que se experimenta son los más permanentes, porque si algunos se han huydo de los tercios de gallegos, son los que alla tenian el cariño hacienda y otras comodidades" 83 . Todos estos factores hacían que al final los enviados a Flandes fueran generalmente jóvenes solteros de las familias más humildes del reino, que quizá con el tiempo no hubieran tenido más remedio que abandonar sus hogares para ganarse el sustento en Castilla. Un buen ejemplo de la calidad de los reclutados lo tenemos durante el año 1674, en el que el reino se comprometió a reclutar un tercio de 1.400 hombres para Flandes, bajo el mando del Conde de Amarante. Los soldados repartidos a las siete provincias del reino fueron llegando progresivamente a La Coruña, en donde una parte de los soldados fueron rechazados por los oficiales reales, ya fuera por ser demasiado viejos y enfermos, o demasiado jóvenes para empuñar las armas, por lo que las propias provincias hubieron de sustituirlos por otros. Finalmente se embarcaron 1.255 plazas entre oficiales y soldados, de los que 46 eran voluntarios reclutados a costa de la Corona mientras que el resto de los hombres fueron aportados por las diferentes provincias, siendo los oficiales también naturales de las mismas. En la leva la mayoría de los alistados fueron "mozos de 18 hasta 25 años de hedad, de famosa apariencia”, según determinaron los informes aportados por los oficiales que pasaron muestra a los hombres ${ }^{84}$.

El servicio de los soldados gallegos casi siempre fue bien visto por los oficiales del ejército de Flandes, especialmente tras el gran contingente llegado en 1668 y las

82 Junta de Tenientes Generales, 15 de noviembre 1693 y 5 de febrero 1694. A.G.S. G.A. Leg. 2.916 y 2.917.

83 Proposición del Conde de Monterrey, 1 de julio 1671. A.G.S. G.A. Leg. 2.220.

84 Consejo de Guerra, 6 de abril 1674, con carta inclusa del Conde de Aranda. Informe del veedor del reino de Galicia, 22 de noviembre 1681. A.G.S. G.A. Leg. 2.301 y 2.581. 
continuas reclutas enviadas en la década siguiente. Uno de los principales motivos por el que se pedían gran cantidad de reclutas en Galicia para Flandes era por la calidad de los reclutados, que además perseveraban en el servicio de las armas cuando otros muchos españoles no lo hacían ante la falta de comodidad y pagas ${ }^{85}$. Como bien decía el Conde de Monterrey en 1671, veterano militar llegado a Flandes en 1666: "se ha visto la poca permanencia que aqui tienen en lo general de algunas provincias de España que por apacibles y regaladas les hacen penosa esta vida tan estrecha y miserable, y más quando como es notorio han llegado a vivir tanto tiempo continuado reducidos a la vileza de mendigar por no morir, causa que a tantos ha obligado a faltar del servicio" "86. Esta circunstancia hacia si cabe más útiles a los reclutas gallegos, que se mantenían donde otros no soportaban sobrevivir, de ahí las notables alabanzas del Conde de Monterrey a los soldados gallegos que militaban en el ejército de Flandes:

"De todas las provincias de España ninguna produce gente tan apropósito para mantenerse en estos estados como el reyno de Galicia, donde la esterilidad y miseria en que se mantienen aquellos naturales, y la gran docilidad que les acompaña para la obediencia y robustez para el trabajo les hace no sentir la cortedad y mal mantenimiento y la calidad en lo general el valor de españoles para todo lo que es de su obligación parece les limita otras ambiciones experimentandose ay aqui en los tercios que ay desta nacion que en ellos, más que en otros de españoles, resplandece la disciplina militar y obediencia, la permanencia en el servicio y viven sanos robustos y bien vestidos con lo mismo que otros están miserables... Devese notar otra circustancia particular en ellos que como tan retirados del comercio y criados en tierra corta es raro el que está bien hallado con los de otras provincias sino es persona particular o despues de haver militado muchos años en los exercitos" $" 87$.

A pesar del agasajo mostrado por el Conde de Monterrey a los soldados gallegos parezca exagerado, éstos siempre demostraron en Flandes buena actitud militar. Uno de los motivos era que desde 1668 y durante toda le década siguiente llegaron a Flandes multitud de soldados gallegos, la mayor parte de ellos experimentados y veteranos del largo conflicto fronterizo con Portugal. Esto suponía que la mayor parte de los oficiales, aunque elegidos generalmente por el propio reino gracias a las patentes en blanco, tenían la experiencia necesaria para desempeñar sus cargos.

85 Proposición del Conde de Monterrey, 1 de julio 1671. Carta de don Diego Sarmiento, 5 de septiembre 1671. A.G.S. G.A. Leg. 2.220.

86 Proposición del Conde de Monterrey, 1 de julio 1671. A.G.S. G.A. Leg. 2.220.

87 Ibidem. 
Pero los problemas empezaron a aparecer en las aportaciones del reino de finales de siglo. En 1689 en Galicia se ajustó el reclutamiento de 3.000 hombres en tres nuevos tercios. Aunque los hombres que llegaron a Flandes eran de buena calidad y estaban bien armados y vestidos, los oficiales del ejército de Flandes no quedaron demasiado satisfechos de la leva. Con estas palabras se refirió a ellos el gobernador de los Países Bajos: "esta gente no es mala, viene bien vestida y armada, pero sumamente vozal en el manejo de las armas, y los oficiales son visoños". El verdadero problema era, sin duda, la poca experiencia que demostraban los hombres en el manejo de las armas, algo que se complicaba aún más por el hecho de que la mayoría de sus oficiales no tenían la suficiente experiencia. En aquella época la mayoría de los soldados y oficiales gallegos llegados a Flandes ya no tenían la instrucción militar de sus homólogos de décadas anteriores. Estos hombres no habían servido en la guerra contra Portugal, como había ocurrido años atrás, por lo que una gran parte de los soldados y oficiales atestiguaban una notable inexperiencia en la milicia. Ahora estos hombres no habían visto la guerra, por lo que a penas sabían usar un arma. La generación de gallegos curtidos en la guerra de Portugal había llegado a su fin. Pese a esta problemática sobre la calidad de los hombres llegados, según las palabras del Marqués de Gastañaga, Gobernador de los Países Bajos, estos tercios fueron un "gran socorro" de hombres para Flandes ${ }^{88}$.

Otros factores considerables que hacían que tras el fin de la guerra con Portugal los soldados gallegos fueran enviados a Flandes eran la facilidad del embarque y la mayor efectividad de éstos en ese frente alejado que en Cataluña u otros puntos. Como bien se decía en 1692 "la gente de Galicia no es apropósito para la cavallería ni aún para la infantería en los exercitos de España, por cuia causa siempre se ha embiado a Flandes donde lo han provado bien". Pero posiblemente el factor definitivo de esto, y el motivo de esta causa, era la gran distancia que separaba Galicia del principado de Cataluña, lo que hacía que el transporte terrestre no fuera fácil. Este camino se debía recorrer a pie, por lo que se veía muy poco aconsejable las levas de gallegos para este frente por las continuas fugas y gastos que tendrían lugar durante el transporte, además de que se temía que muchos soldados desertaran a su paso por Castilla al encontrar trabajo fácilmente como jornaleros ${ }^{89}$. Aunque repetidos informes atestigüen la ineficiencia del reclutamiento de gallegos para el servicio en España, lo cierto es que generalmente los españoles que servían en la península no eran

88 Cartas del Marqués de Gastañaga, Gobernador de los Países Bajos, 1 de septiembre y 26 de octubre 1689. Consejo de Estado, 8 de octubre 1689. Relación de los oficiales, soldados que hay en las compañías de infantería que han llegado de Galicia, 4 de septiembre 1689. A.G.S. Estado Leg. 3.882.

89 Junta de Disposiciones de Campaña, 6 de diciembre 1692. A.G.S. G.A. Leg. 2.887. 
bien considerados como soldados, debido a la facilidad de las fugas por la cercanía de sus hogares, por lo generalmente los mismos soldados eran mucho más valorados en Flandes o Italia donde eran considerados las mejores tropas ${ }^{90}$.

Siempre que se intentaba enviar a Flandes un importante número de hombres desde Galicia se planteaba la creación de un nuevo tercio. La medida, aunque era más cara para la Corona, suponía una mayor conformidad en el reino, teniendo la leva un mayor apoyo en su formación, encontrando los militares un espíritu de cuerpo que les mantenía unidos. A su vez la mayor parte de los oficiales de estas unidades eran naturales del reino, lo que hacía que los tercios tuvieran una mayor cohesión. La creación de nuevos tercios venía motivada por la necesidad práctica, ya que se decía de los gallegos que “...su buena y segura conservación pide sean mantenidos en cuerpos enteros de su provincia, mandados por naturales della y no por otros" "91. Ante los continuos informes sobre el tema la Corona siempre intentó complacer al reino y a los nuevos reclutas, aunque no siempre las necesidades hacendísticas lo permitan.

Con el importante transvase de efectivos del ejército de Galicia al de Flandes en 1668 se implantarán definitivamente en el ejército de Flandes dos de los denominados tercios pilones del reino, los de don Fernando Valladares y don Pedro Aldao, que se mantendrán en los Países Bajos durante largos años, al igual que el trozo de caballería denominado Galicia. Incluso el tercio de infantería de Pedro Aldao permanecerá en territorio flamenco hasta el advenimiento de Borbones y la evacuación de los Países Bajos $^{92}$. Con posteridad otras unidades permanecerán durante años en Flandes antes de ser reformadas y pasar sus hombres a otras unidades del ejército, intentándose siempre que parte de sus efectivos pasasen a otros tercios formados por gallegos. Los problemas comenzarán durante mediados de la década de 1670, cuando la dureza de la Guerra de Holanda y la falta de nuevas reclutas en otras partes de España hagan que los tercios españoles del ejército de Flandes queden muy menoscabados de personal, por lo que ante esa situación la veeduría flamenca tomará la resolución de suprimir las unidades más recientes para ahorrar sueldos de oficiales, pasando los soldados al resto de los tercios veteranos, para que estos reemplacen sus bajas. La falta de reclutas y esta medida económica afectarán a los tercios gallegos, que continuamente serán reformados, incluso alguno de ellos nada más desembarcar ${ }^{93}$.

90 Carta del Marqués de Castel-Rodrigo, Gobernador de los Países Bajos, 7 de septiembre 1667. A.G.S. Estado Leg. 2.106.

91 Proposición del Conde de Monterrey, 1 de julio 1671. A.G.S. G.A. Leg. 2.220.

92 SAMANIEGO, Juan Antonio: Disertación sobre la antigüedad de los Regimientos, Madrid, 1992, pp. 115-117. Original de 1738.

93 Diversas órdenes de reforma de unidades. Archives Générales du Royaume de Bruxelas (A.G.R.B.) Secrétariat d'Etat et de Guerre T. 100 N. 77 y 79 
Tabla VII: Los tercios gallegos en el ejército de Flandes (1668-1700):

\begin{tabular}{|c|c|c|c|}
\hline Año de llegada & Reclutas & Evolución & Duración \\
\hline 1668 & Tercio de don Fernando Valladares & Reformado en 1682 & 14 años \\
\hline 1668 & Tercio de don Pedro Aldao & $\begin{array}{l}\text { Al pasar los tercios a regimientos fue } \\
\text { denominado Toro y poco después Por- } \\
\text { tugal, se mantuvo hasta } 1749\end{array}$ & $\begin{array}{l}\text { Hasta el } \\
\text { siglo XVIII }\end{array}$ \\
\hline 1668 & Trozo de Galicia (Caballería) & Reformado en 1681 & 13 años \\
\hline 1674 & Tercio del Conde de Amarante & $\begin{array}{l}\text { Reformado en marzo 1681, parte de } \\
\text { sus hombres pasaron a los otros ter- } \\
\text { cios gallegos }\end{array}$ & 7 años \\
\hline 1675 & $\begin{array}{l}\text { Cinco compañías del Tercio del Marqués } \\
\text { de Arcos Tenorio (el resto del tercio es- } \\
\text { taba compuesto por soldados reclutados } \\
\text { en Asturias) }\end{array}$ & $\begin{array}{l}\text { Reformado en julio 1677, parte de sus } \\
\text { hombres pasaron a los otros tercios } \\
\text { gallegos }\end{array}$ & 2 años \\
\hline $1676-77$ & Tercio de don Manuel Sarmiento & $\begin{array}{l}\text { Reformado en julio 1677, parte de sus } \\
\text { hombres pasaron a los otros tercios } \\
\text { gallegos }\end{array}$ & 9 meses \\
\hline 1680 & Tercio del Conde de Grajal (4 compañías) & Reformado al Ilegar & Meses \\
\hline 1684 & Tercio de don Antonio Mariño & $\begin{array}{l}\text { Reformado poco después de su lle- } \\
\text { gada, el Maestre de Campo pasa a } \\
\text { serlo de un tercio veterano al igual que } \\
\text { parte de sus hombres }\end{array}$ & Meses \\
\hline 1689 & $\begin{array}{l}\text { Tres tercios: Marqués de Casasola, don } \\
\text { Jacinto Sarmiento Zamudio y don Pedro } \\
\text { de Aldao }\end{array}$ & Reformados todos durante 1693 & 4 años \\
\hline
\end{tabular}

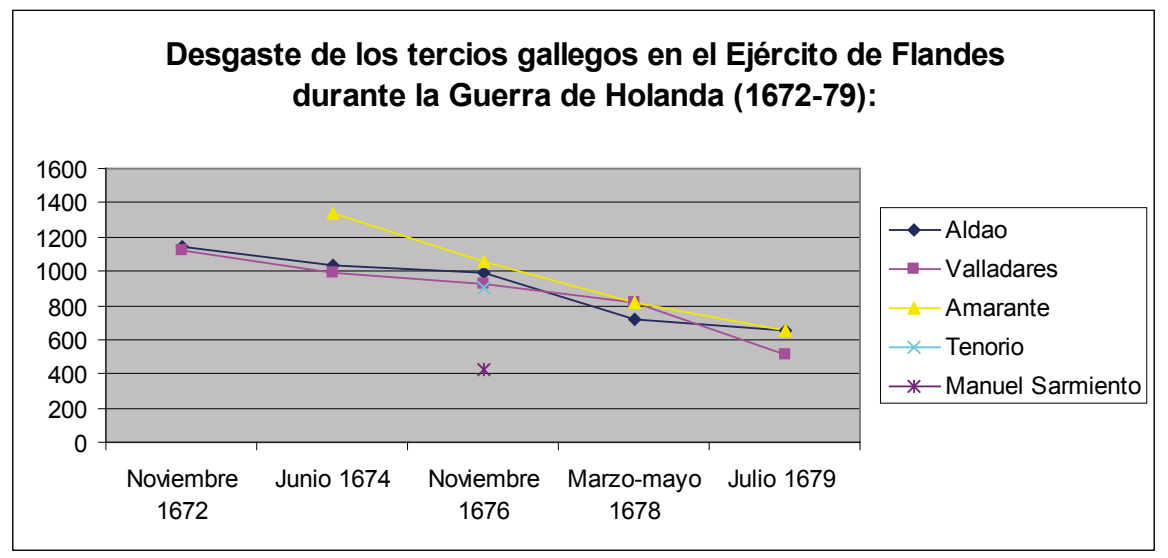

Fuente: A.G.S. Estado Leg. 2.121, 2.126, 2.133, 3.862 y 3.865. 